\title{
Expert Recommendations on the Usage of Non- vitamin K Antagonist Oral Anticoagulants (NOACs) from India: Current Perspective and Future Direction
}

\author{
Balbir Singh - Paresh Pai - Harish Kumar - Sheeba George · \\ Sandeep Mahapatra • Vineet Garg · G. N. Gupta - Kiran Makineni · \\ Gaurav Ganeshwala · Pravin Narkhede · Syed M. H. Naqvi · \\ Kumar Gaurav · Mohammed Y. K. Hukkeri
}

Received: October 27, 2021 / Published online: February 8, 2022

(C) The Author(s) 2022

\section{ABSTRACT}

Non-vitamin K antagonist oral anticoagulants (NOACs) are a new class of anticoagulant drugs used in the prevention and treatment of venous thromboembolism (VTE) and atrial fibrillation (AF). Anticoagulation requires the integration of the correct type and dose of oral anticoagulants based on patient characteristic, and therefore therapy needs to be individualized for each patient. Growing scientific evidence from studies on NOACs has led to a better understanding of their benefits and safety. A large amount of available data creates a necessity for

B. Singh

Max Super Speciality Hospital, Saket, New Delhi, India

P. Pai

Lilavati Hospital and Research Centre, Mumbai, Maharashtra, India

H. Kumar

Moorthy Hospital Pvt. Ltd., Trichy, Tamil Nadu, India

S. George

Sree Mookambika Institute of Medical Sciences,

Thiruvananthapuram, Kerala, India

S. Mahapatra

Nizam's Institute of Medical Sciences, Hyderabad, India

V. Garg

Blossoms Hospitals, Agra, Uttar Pradesh, India an adaptable practical document for the usage of NOACs in India. The current consensus, developed by experts from India, aims to give recommendations on various frequently raised clinical questions with regards to NOACs and its usage. This practical document provides a platform upon which future guidelines, policies, training, and education for the use of NOACs can be tailored.

Keywords: Anticoagulants; Venous thromboembolism; Atrial fibrillation; Rivaroxaban; Apixaban; Edoxaban

\section{G. N. Gupta}

Gupta Heart and Medical Centre, Gorakhpur, Uttar Pradesh, India

\section{K. Makineni}

Kirans Vascular Surgery Centre, Vijayawada, Andhra

Pradesh, India

G. Ganeshwala

Ruby Hall Clinic, Pune, Maharashtra, India

P. Narkhede

PVS Clinic, Nashik, Maharashtra, India

S. M. H. Naqvi · K. Gaurav ( $₫)$ - M. Y. K. Hukkeri Dr. Reddy's Laboratories Ltd., 8-2-337, Road No. 3, Banjara Hills, Hyderabad, Telangana 500034, India e-mail: kumargaurav2@drreddys.com 


\section{Key Summary Points}

Despite the complexity of the prevention and management of venous thromboembolism (VTE) and nonvalvular atrial fibrillation (NVAF), there are no specific guidelines in India and international guidelines are not standardized in the country.

Non-vitamin K antagonist oral anticoagulant (NOACs) have been approved as alternatives to warfarin and other vitamin $\mathrm{K}$ antagonists (VKA) for the prophylaxis of stroke and systemic embolic events (SEE) in patients with NVAF, and for treatment and prophylaxis of VTE.

NOACs significantly reduce stroke or systemic embolic events, hemorrhagic stroke, intracranial hemorrhage, and major bleeding in patients with VTE. Though both NOACs and VKAs can be used for the prevention of VTE, NOACs have a more significant relative reduction in major bleeding.

The dose and duration of NOAC therapy should be individualized after careful assessment of the treatment benefit against the risk of bleeding.

\section{EXPERT GROUP \\ RECOMMENDATIONS}

\section{Venous Thromboembolism}

1. NOACs or VKAs can be used for the prevention of recurrent VTE.

2. In VTE, NOACs compared to VKA have a significant relative reduction in major bleeding.

3. The decision of a once-daily or twice-daily NOAC regimen in VTE should be based on patient characteristics and clinical condition.

4. The duration of NOAC therapy should be individualized after careful assessment of the treatment benefit against the risk of bleeding. Short duration of therapy (at least 3 months) should be based on transient risk factors (e.g., recent surgery, trauma, and immobilization) and longer durations should be based on permanent risk factors or idiopathic deep vein thrombosis (DVT)/ pulmonary embolism (PE).

5. NOACS or other anticoagulants such as VKA and low molecular weight heparin (LMWH) can be used in chronic kidney disease (CKD) patients with VTE.

6. NOACs should be the first choice among currently available anticoagulants in elderly patients.

7. NOACs or LMWHs can be used in cancer patients with VTE.

a) Precaution for high risk of bleeding, as those with gastrointestinal and genitourinary cancer.

\section{Atrial Fibrillation (AF)}

1 NOACs compared to warfarin significantly reduced stroke or systemic embolic events, hemorrhagic stroke, intracranial hemorrhage, and major bleeding in patients with VTE.

2 Once- or twice-daily NOAC regimen can be used in patients with atrial fibrillation (AF).

3 Duration of therapy in AF must be individualized after careful assessment of the treatment benefit against the risk of bleeding. For patients with AF of greater than $48 \mathrm{~h}$ or unknown duration undergoing elective electrical or pharmacologic cardioversion, it is recommended that therapeutic anticoagulation should be started for at least 3 weeks before cardioversion and should be continued for at least 4 weeks post successful cardioversion. Decisions about anticoagulation beyond 4 weeks should be made in accordance with risk-based 
recommendations for long-term antithrombotic therapy and not based on successful cardioversion.

4 In AF patients eligible for NOACs, it is recommended to use a NOAC in preference to a VKA in combination with antiplatelet therapy.

5 In CKD patients, stage 1-3: NOACs are preferred. In CKD stage 4: NOACs or warfarin, the choice between will depend on the pharmacokinetics of the drugs and patient characteristics. In End-stage renal disease (ESRD): Warfarin remains the first-line treatment (to use or not to use anticoagulation is strictly individualized).

6 NOACs may be preferred in elderly patients, since they have a better overall risk-benefit profile compared with warfarin.

\section{Venous Thromboembolism or Atrial Fibrillation}

1 Mild hepatic impairment: All NOACs could be considered without any dose adjustments.

Moderate hepatic impairment: Dabigatran, apixaban, and edoxaban are viable options in patients with moderate hepatic impairment and do not require dose adjustments. Severe hepatic impairment: All NOACs are contraindicated. Warfarin is the only recommended anticoagulant in this patient population.

2 Any NOAC can be used in obese patients with body mass index (BMI) $<40 \mathrm{~kg} / \mathrm{m}^{2}$. In patients with a BMI of $40-50 \mathrm{~kg} / \mathrm{m}^{2}$, warfarin should be used, but apixaban or edoxaban can be considered. In obese patients with a BMI $>50 \mathrm{~kg} / \mathrm{m}^{2}$, warfarin should be used.

3 Factors to consider when choosing an oral anticoagulant include compliance, renal function, history of GI bleeding, concomitant medication, age, the need for aspirin, dosing, and cost. It is important to stratify the risk of stroke and hemorrhage for an individual patient before selecting OAC.

4 For re-starting NOAC post-procedurerestart 2 days after a high bleeding risk procedure and restarted 1 day after a low/moderate bleeding risk procedure.

5 Reversal agents are indicated in patients with major bleed. Non-major/minor bleed-reversal agents not required, withholding the next NOAC doses is sufficient. The choice of NOAC should not be based on the availability of its respective reversal agents.

6 In case of a missed dose, the forgotten dose can be taken up to $6 \mathrm{~h}$ or up to $12 \mathrm{~h}$ after the scheduled intake for a $\mathrm{BD}$ or $\mathrm{OD}$ regimen, respectively. If this is not possible, the dose should be skipped and the next scheduled dose taken. In case of a double dose on a BD regimen, the next planned dose can be skipped and restarted BD after $24 \mathrm{~h}$ while in OD dosing, the normal regimen can be continued. In case of overdose, dabigatran can be removed via dialysis. Rivaroxaban and apixaban are not dialyzable, hence use reversal agents.

\section{INTRODUCTION}

Venous thromboembolism (VTE) and atrial fibrillation (AF) implicate a high burden of mortality and morbidity. In India, about 2,31,132 VTE events occur annually and $53.6 \%$ of the hospitalized Indian patients are at an increased risk of VTE. The age group commonly affected with VTE is 41-60 years [1]. General surgery and orthopedics department observe a higher incidence of VTE [2]. The burden of AF in India is high due to the high prevalence of the associated risk factors, especially hypertension and diabetes mellitus. Prophylaxis of AF and VTE is a cost-effective measure, as costs of management of deep vein thrombosis (DVT) and pulmonary embolism (PE) are very high [3]. The rising incidence of VTE across India may be attributable to the aging population, dietary changes, and increasing incidence of obesity and diabetes. $\mathrm{AF}$, an important risk factor for cardioembolic stroke, is the most common sustained cardiac arrhythmia [4, 5]. In India, valvular AF patients comprise not just those with mechanical heart valves but also those 
with rheumatic mitral stenosis. There has been a steady increase in AF incidence over the last two decades. This trend is likely to continue over the next few decades with an aging population and higher occurrence of the associated risk factors, including cardiac diseases. Despite major advances in its management, AF remains a significant cause of cardiovascular morbidity and mortality, especially that arising from stroke and heart failure (HF) [6].

Non-vitamin K antagonist oral anticoagulant (NOACs) have been approved as alternatives to warfarin and other vitamin $\mathrm{K}$ antagonists (VKA) for the prophylaxis of stroke and systemic embolic events (SEE) in patients with nonvalvular atrial fibrillation (NVAF), treatment, and prophylaxis of VTE. The NOACs fall into two major categories: direct thrombin (factor IIa) inhibitors (dabigatran) and direct factor Xa inhibitors (rivaroxaban, apixaban, and edoxaban). Several clinical trials have proved these agents as safe and efficacious [3]. In addition, they have added advantages such as rapid onset and termination of the action, predictable anticoagulant effect such that routine laboratory monitoring is not required [5-9]. For patients with DVT and/or PE, the American Society of Hematology (ASH) guideline 2020 panel suggests using NOACs over VKAs (conditional recommendation) [10]. Atrial fibrillation increases mortality and many cardiovascular and cerebrovascular events, including $\mathrm{HF}$ and acute coronary syndrome (ACS) [11]. NOACs significantly reduce stroke or systemic embolic events by $19 \%$ compared with warfarin [12].

Warfarin and other VKAs antagonists have several limitations that make it difficult to use in clinical practice. Warfarin, the conventional oral anticoagulant has several limitations and challenges, such as resistance due to VKORC1 genetic polymorphisms, a narrow therapeutic window with international normalized ratio (INR) range 2-3, routine coagulation monitoring, unpredictable pharmacokinetics, slow-onset/offset of action, increased risk of bleeding including intracranial hemorrhage, dose adjustment, dietary restrictions, drug interactions, high coefficient of inter-lab variation in INR estimation; INR is not reflective of monthly or long-term control $[13,14]$.

\section{The Extent of the Problem}

Patients who develop a VTE are more likely to have an extended hospital stay with additional economic costs, mainly attributable to the extended length of stay. Indirect costs, such as loss of productivity by the patient and an increased burden on their careers, further add to the economic cost of thromboembolism to healthcare systems. The incidence of VTE may be influenced by rising rates of urbanization, reduced medical adherence, hypertension, diabetes, obesity, knee replacement, and other elective surgeries [1-3].

\section{Need for Consensus}

The prevention of VTE is complex and requires the integration of a correct choice and dosing of an oral anticoagulant (OAC). Between 2009 and 2013, four different compounds were compared with conventional therapy for the treatment of acute VTE and NVAF. In total, 27,023 patients were enrolled in six phase 3 randomized controlled trials. Clinicians will need to choose between these new anticoagulants and standard treatment, and they will need clinically relevant information as to whether these agents are indeed suited for all of their patients with VTE. Furthermore, stoppage and restarting of NOACs are critical before and after surgery. However, there are no specific guidelines in India and international guidelines are not standardized in the country. Hence, there is a need for an adaptable practical document for oral anticoagulants for VTE and AF in India. To aid the clinician in dealing with the overwhelming amount of information, we present a draft recommendation on various frequently raised clinical questions.

\section{Methods}

The primary target audience for this practical document is surgeons and nurses. The recommendations are also intended to be used by policy-makers as the basis for developing national and local anticoagulation protocols and policies and supporting staff education and 
training. A diverse group of practitioners was therefore chosen for the expert panel to represent a wide and holistic view on NOAC for prevention and treatment of AF and VTE. The main aim of this practical document is to give recommendations for better patient outcomes and services in all types of hospitals. Therefore, the experts were asked to deliberate on NOACs for AF and VTE from an Indian perspective. This article is based on previously conducted studies and does not contain any new studies with human participants or animals performed by any of the authors.

\section{NOACS IN VTE}

\section{Why are NOACs Chosen over VKAs for the Treatment of VTE?}

In the last 4 years, six phase 3 trials including a total of 27,023 patients with venous thromboembolism (VTE) compared a NOAC with VKA. Recurrent VTE occurred in $2.0 \%$ of NOAC recipients compared with $2.2 \%$ in VKA recipients (relative risk [RR] 0.90). Treatment with a NOAC significantly reduced the risk of major bleeding (RR 0.61). In parallel, intracranial bleeding, fatal bleeding, and clinically relevant non-major bleeding occurred significantly less in NOAC recipients. Factor $\mathrm{Xa}$ inhibitors (NOACs) were as effective as VKAs in the prevention of recurrent VTE, with a significant relative reduction of $44 \%$ in major bleeding. NOACs are safe and effective in key clinical groups such as patients with PE, DVT, a bodyweight $\geq 100 \mathrm{~kg}$, moderate renal insufficiency, an age $\geq 75$ years, and cancer [7].

The ASH 2020 guidelines recommend using NOACs over VKAs in patients with DVT and/or PE The use of a NOAC instead of a VKA for patients with VTE does not impact mortality $(\mathrm{RR}=0.99$; or the risk of PE RR $=0.97)$. The use of a NOAC was associated with a reduction in the risk of major bleeding $(\mathrm{RR}=0.63)$. Patients with a high bleeding risk may benefit from a NOAC instead of a VKA in terms of fewer bleeding events per 1000 patients [10].

\section{Risk Assessment of VTE Patients About to Start Anticoagulation Treatment}

Several scoring systems such as the Vienna prediction model (VPM), DASH score, and the HERDOO2 scoring system are used to predict the risk of recurrence of VTE after a first unprovoked episode. The Vienna prediction model calculates the cumulative recurrence risk (CRR) of VTE using different parameters like sex, location of the first VTE event, and d-dimer level after cessation of anticoagulation [15]. The VPM could aid clinicians in estimating this risk, thus help in deciding the dose and duration of the prescribed NOAC. The updated VPM integrates patient's parameters and serial d-dimer measurements allowing prediction of recurrent VTE from multiple random times after discontinuation of oral anticoagulation [16]. The initial treatment of VTE is based on patient characteristics (Fig. 1).

\section{NOAC Dose for the Treatment and Prevention of VTE}

Dosing of NOACs in patients with VTE.

Table 1 describes the dosing regimen of NOACs for initial treatment and secondary prevention of VTE [18].

\section{Once- or Twice-Daily NOAC Therapy in VTE}

A meta-analysis of 12 RCTs and 10,716 patients, compared different regimens of all NOACs,

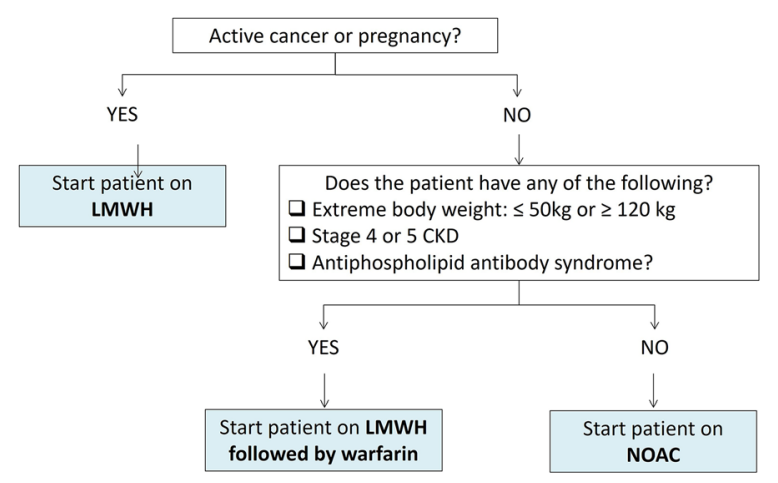

Fig. 1 Initial treatment of VTE [17]. CKD chronic kidney disease, $L M W H$ low molecular weight heparin 
Table 1 Dosing of NOACs in patients with VTE [18]

\begin{tabular}{|c|c|c|}
\hline NOAC & VTE initial treatment & VTE secondary prevention after initial therapy \\
\hline Apixaban & $\begin{array}{l}10 \mathrm{mg} \text { orally twice daily for the first } 7 \text { days of } \\
\text { therapy followed by } 5 \mathrm{mg} \text { orally twice daily }\end{array}$ & $\begin{array}{l}\text { After } \geq 6 \text { months of initial therapy, either } 5 \mathrm{mg} \text { orally twice } \\
\text { daily or } 2.5 \mathrm{mg} \text { orally twice daily can be considered }\end{array}$ \\
\hline Dabigatran & $\begin{array}{l}150 \mathrm{mg} \text { orally twice daily when preceded by } \\
5-10 \text { days of parenteral AC }\end{array}$ & $150 \mathrm{mg}$ orally twice daily \\
\hline Edoxaban & $\begin{array}{l}60 \text { mg orally once daily when preceded by at } \\
\text { least 5-10 days of parenteral AC }\end{array}$ & $60 \mathrm{mg}$ orally once daily \\
\hline Rivaroxaban & $\begin{array}{l}15 \mathrm{mg} \text { orally twice daily with food for the } \\
\text { first } 21 \text { days followed by } 20 \mathrm{mg} \text { daily with } \\
\text { food }\end{array}$ & $\begin{array}{l}\text { After } \geq 6 \text { months of initial therapy, either } 20 \mathrm{mg} \text { orally daily } \\
\text { with food or } 10 \mathrm{mg} \text { orally daily with or without food can } \\
\text { be considered }\end{array}$ \\
\hline
\end{tabular}

$A C$ anticoagulant

concluded that there is no difference in efficacy and safety between the once daily (OD) and twice daily (BD) regimens of NOACs in patients with VTE, NVAF, ACS and major orthopedic surgery (MOS) [19]. Rivaroxaban OD regimens were studied in various VTE trials such as RECORD and EINSTEIN-EXT. Most studies suggest that once-daily dosing may be suitable for most rivaroxaban indications including VTE and AF. The elimination half-life $\left(t_{1 / 2}\right)$ of rivaroxaban is prolonged in elderly patients, thus rivaroxaban OD may be suitable for geriatric patients. Thus, a "one-size-fits-all" approach regarding frequency may not be the right choice for patients. Thus, both patient and drug characteristics must be considered [20].

The anticoagulant effects of edoxaban are rapid in onset ( $T_{\max } 1-2 \mathrm{~h}$ ) and sustains for up to $24 \mathrm{~h}$ [21]. The Hokusai VTE study demonstrated edoxaban $60 \mathrm{mg}$ orally once daily to be non-inferior to warfarin for VTE recurrence [HR 0.89] [22]. The efficacy of twice daily dose of apixaban was observed in AMPLIFY and AMPLIFY-EXT study [23, 24]. The AMPLIFY study patients received apixaban $10 \mathrm{mg}$ twice daily orally for 7 days followed by apixaban $5 \mathrm{mg}$ twice daily orally for 6 months. AMPLIFYEXT study patients received apixaban $2.5 \mathrm{mg}$ orally twice daily or $5 \mathrm{mg}$ orally twice daily for 12 months. Both studies demonstrated non-inferiority of apixaban to enoxaparin/warfarin and superiority to placebo for recurrent symptomatic VTE.

\section{Duration of NOAC Therapy in VTE Patients}

Approved dose and duration regimens of NOACs for the treatment of VTE is mentioned in Fig. 2.

For rivaroxaban, a reduction in the dose from 20 to $15 \mathrm{mg}$ OD should be considered if the patient's assessed risk of bleeding outweighs the risk of recurrent DVT/PE. Rivaroxaban should be used with caution in patients with creatinine clearance $(\mathrm{CrCl})$ of $15-29 \mathrm{ml} / \mathrm{min}$ and is not recommended in patients with $\mathrm{CrCl}<15 \mathrm{ml} / \mathrm{min}$. For apixaban, the prevention of recurrent DVT or PE following completion of 6 months of treatment for DVT or PE, $2.5 \mathrm{mg}$ twice daily (BD) is recommended. Apixaban should be used with caution in patients with $\mathrm{CrCl} 15-29 \mathrm{ml} / \mathrm{min}$ and is not recommended in patients with $\mathrm{CrCl}<15 \mathrm{ml} / \mathrm{min}$. For dabigatran, the dose should be selected based on individual assessment of the thromboembolic and bleeding risks: age 75-80 years; moderate renal impairment; gastritis, esophagitis, or gastroesophageal reflux, and increased risk of bleeding. Dabigatran is contraindicated in patients with severe renal impairment $(\mathrm{CrCl}<30 \mathrm{ml} / \mathrm{min})$. For edoxaban $30 \mathrm{mg}$, OD is recommended in patients with one or more of the following clinical factors: moderate or severe renal impairment $(\mathrm{CrCl} 15-50 \mathrm{ml} / \mathrm{min})$, low body weight $(<60 \mathrm{~kg})$, or concomitant use of 

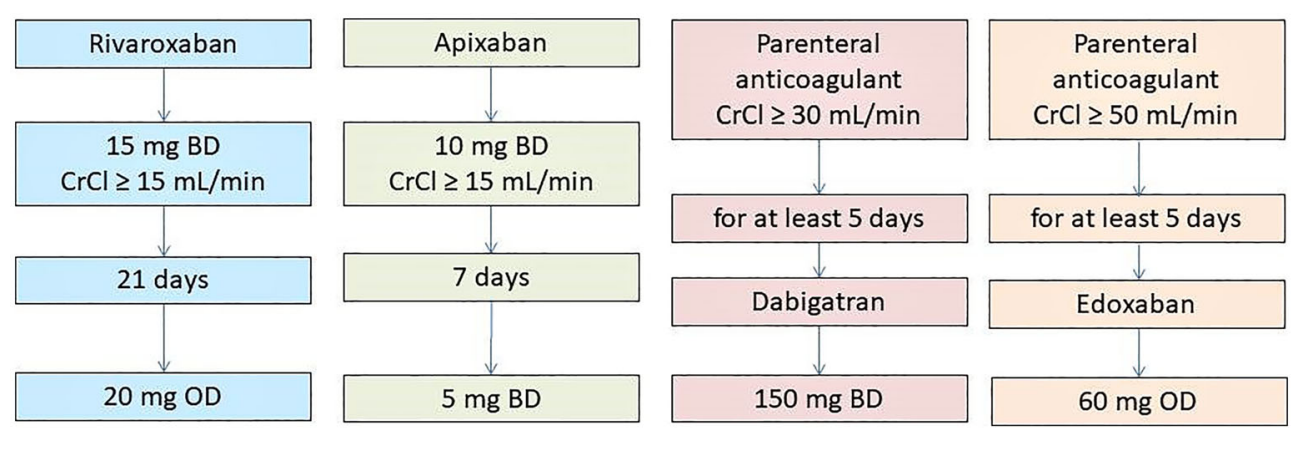

Fig. 2 Dose regimens of the NOACs (based on the EU labels) for the treatment of VTE [25]. OD once-daily, $B D$ twicedaily, $\mathrm{CrCl}$ creatinine clearance

the following P-gp inhibitors: cyclosporin, dronedarone, erythromycin, or ketoconazole [25].

\section{Special Population}

\section{Chronic Kidney Disease (CKD) and VTE}

NOACS and other anticoagulants including VKA and LMWH showed no statistical difference in preventing recurrent VTEs among CKD patients. NOACs had a significantly lower risk of major and non-major clinically relevant bleeding irrespective of the level of renal impairment compared to VKAs [18].

The Italian Society of Nephrology suggests that NOAC have at least similar efficacy and safety profiles as VKA in patients with CKD stage $\mathrm{G} 2 \quad(\mathrm{CrCl} \quad 60-89 \mathrm{ml} / \mathrm{min})$ to $\mathrm{G} 3 \mathrm{~b}$ (30-44 ml/min), while in patients with CKD G4 $(15-29 \mathrm{ml} / \mathrm{min})$ to $\mathrm{G} 5(<15 \mathrm{ml} / \mathrm{min})$, also on long-term dialysis, NOAC should be used with caution. Careful monitoring of renal function in patients taking NOAC is recommended to avoid the risk of overdosing [26].

\section{The Elderly and Frail with VTE}

The incidence of VTE and VTE-related morbidity and mortality increases with advancing age. Thus, in elderly patients, NOACs are not only associated with a lower risk of bleeding but they even appear to be more efficacious than vitamin $\mathrm{K}$ antagonists in preventing recurrent VTE during the acute treatment period [15]. Using NOAC in elderly patients has been associated with a superior efficacy profile and no increase in bleeding events, compared to conventional anticoagulation. Thus, NOACs should be the first choice among currently available anticoagulants in elderly patients [27]. In non-AF trials, NOACs also had a significantly lower risk of VTE or VTE-related death than conventional therapy in elderly adults [28]. In the absence of conclusive data, standard dose of NOAC is initially prescribed to elderly patients with acute VTE. But, since lower dose of apixaban and rivaroxaban are effective and have a lower risk of bleeding in extending treatment of VTE, it is suggestive to consider these lower doses in elderly requiring long-term anticoagulation for preventing recurrent VTE [29].

recurrent VTE.

\section{Cancer and VTE}

Patients with cancer-associated venous thrombosis (CAT) have an elevated risk of both recurrent VTE, due to their prothrombotic status, and bleeding complications, due to the cancer lesion, chemotherapy, and related thrombocytopenia. In patients with cancer, results from recent randomized trials have reported that the efficacy and safety profile of NOACs does not differ from those of LMWHs. Thus, NOACs are a valid option for the treatment of VTE in these patients. However, for the management of cancer patients at high risk of bleeding, as those with gastrointestinal and genitourinary cancer who require carefully monitoring, LMWH should be the treatment of choice [18].

Major guidelines recommend the use of LMWH for the treatment of cancer-associated VTE and have recently added the use of 
Table 2 Clinical studies of cancer-associated VTE [31]

\begin{tabular}{|c|c|c|c|c|c|}
\hline Landmark trial & $N$ & Intervention (dose and duration) & Results & & \\
\hline \multirow[t]{6}{*}{ SELECT-D } & \multirow[t]{6}{*}{203} & \multirow{2}{*}{$\begin{array}{l}\text { Dalteparin (200 IU/kg daily during month } 1 \text {, } \\
\text { then } 150 \mathrm{IU} / \mathrm{kg} \text { daily for months } 2-6)\end{array}$} & Outcome & $\mathrm{R}$ & $\mathrm{D}$ \\
\hline & & & Recurrent VTE & 8 & 18 \\
\hline & & Or & 6-month & 4\% (HR 0.43) & $11 \%$ \\
\hline & & \multirow[t]{3}{*}{$\begin{array}{l}\text { Rivaroxaban ( } 15 \mathrm{mg} \text { twice daily for } 3 \text { weeks, } \\
\text { then } 20 \mathrm{mg} \text { once daily for a total of } 6 \text { months) }\end{array}$} & $\begin{array}{l}\text { cumulative } \\
\text { VTE } \\
\text { recurrence rate }\end{array}$ & & \\
\hline & & & $\begin{array}{l}\text { 6-month } \\
\text { cumulative } \\
\text { rate of major } \\
\text { bleeding }\end{array}$ & $6 \%(\mathrm{HR} 1.83)$ & $4 \%$ \\
\hline & & & CRNMB rate & $13 \%(\mathrm{HR} 3.76)$ & $4 \%$ \\
\hline \multirow{6}{*}{$\begin{array}{l}\text { HOKUSAI- } \\
\text { VTE cancer }\end{array}$} & \multirow[t]{6}{*}{1046} & \multirow{2}{*}{$\begin{array}{l}\text { Edoxaban group: LMWH for at least } 5 \text { days } \\
\text { followed by oral edoxaban at a dose of } 60 \mathrm{mg} \\
\text { once daily }\end{array}$} & Outcome & $\mathrm{E}$ & $\mathrm{D}$ \\
\hline & & & $\begin{array}{l}\text { Composite of } \\
\text { recurrent VTE }\end{array}$ & $\begin{array}{c}12.8 \%(\mathrm{HR} 0.97 \\
p=0.006 \text { for }\end{array}$ & $13.5 \%$ \\
\hline & & Or & & non-inferiority) & \\
\hline & & Dalteparin group: SC dalteparin at a dose of & Recurrent VTE & $7.9 \%$ & $11.3 \%$ \\
\hline & & $\begin{array}{l}200 \mathrm{IU} / \mathrm{kg} \text { of body weight once daily for } \\
1 \mathrm{month} \text { followed by dalteparin at a dose of } \\
150 \mathrm{IU} / \mathrm{kg} \text { once daily }\end{array}$ & Major bleeding & $6.9 \%$ & $4 \%$ \\
\hline & & $\begin{array}{l}\text { Treatment duration-at least } 6 \text { months and up } \\
\text { to } 12 \text { months }\end{array}$ & & & \\
\hline \multirow[t]{5}{*}{ CARAVAGGIO } & \multirow[t]{5}{*}{1155} & \multirow{2}{*}{$\begin{array}{l}\text { Apixaban oral } 10 \mathrm{mg} \mathrm{BID} \text { for the first week, } \\
\text { followed by } 5 \mathrm{mg} \text { BID }\end{array}$} & Outcome & $\mathrm{A}$ & $\mathrm{D}$ \\
\hline & & & Recurrent VTE & $5.6 \%$ & $7.9 \%$ \\
\hline & & Or & Major bleeding & $3.8 \%$ & $4 \%$ \\
\hline & & $\begin{array}{l}\text { Dalteparin SC } 200 \mathrm{IU} / \mathrm{kg} \text { QD for the first } \\
\text { month, and then } 150 \mathrm{IU} / \mathrm{kg} \text { QD (up to } \\
18,000 \mathrm{IU} \text { and according to the platelet } \\
\text { count) }\end{array}$ & & & \\
\hline & & Treatment duration -6 months & & & \\
\hline
\end{tabular}

edoxaban or rivaroxaban. In the Caravaggio trial, oral apixaban (10 mg BD for the first 7 days, followed by $5 \mathrm{mg}$ BD) was compared to subcutaneous dalteparin (200 IU/kg OD for the first month, followed by $150 \mathrm{IU} / \mathrm{kg} \mathrm{OD})$ for the treatment of cancer-associated VTE. Apixaban was non-inferior to dalteparin in terms of recurrent VTE (5.6 vs. 7.9\%, $p<0.001$ for noninferiority), without an increased risk of major bleeding (3.8 vs. $4.0 \%, p=0.60$ ) [30]. Results of NOAC in cancer-associated VTE trials are mentioned in Table 2 .

The SELECT D trial is multicenter, randomized, open-label, pilot trial, evaluating rivaroxaban vs. dalteparin. The study enrolled patients with active cancer who had symptomatic PE, incidental PE, or symptomatic lower-extremity proximal DVT. Rivaroxaban compared with 
dalteparin was associated with relatively low VTE recurrence ( 4 vs. 11\%) but higher CRNMB (6-13 vs. $4 \%)$ in cancer patients [32]. The HOKUSAI VTE-Cancer study is an open-label, noninferiority trial that demonstrated noninferiority of oral edoxaban to subcutaneous dalteparin with respect to the composite outcome of recurrent venous thromboembolism or major bleeding. Patients with cancer who had acute symptomatic or incidental VTE were enrolled. The rate of recurrent venous thromboembolism was lower (7.9 vs. $11.3 \%$ ) but the rate of major bleeding was higher with edoxaban (6.9\%) than with dalteparin (4\%) [33]. The CARAVAGGIO trial is a multinational, randomized, controlled, open-label, non-inferiority trial evaluating apixaban vs. dalteparin for the prevention of recurrent VTE in oncologic outpatients. Enrolled patients had symptomatic or incidentally detected proximal lower limb DVT or PE. Apixaban resulted non-inferior to dalteparin for preventing VTE (5.6 vs. $7.9 \%, p<0.001$ for non-inferiority) without increasing the risk of major bleeding ( 3.8 vs. $4 \%, p=0.60$ ) in patients with cancer [24].

A meta-analysis showed that anticoagulant therapy with NOACs (apixaban, edoxaban, rivaroxaban, or dabigatran) may be more effective than traditional anticoagulants (VKA, $\mathrm{LMWH}$, dalteparin, or enoxaparin) to prevent recurrent VTE (RR 0.60, $p<0.00001$ ) in patients with CAT, while the bleeding risk was similar in both groups (RR 0.95, $p=0.79$ ). Thus, NOACs may be more effective than traditional anticoagulants in preventing recurrent VTE in cancer patients, with no significant difference in safety. Hence, NOACs can be used as the first-line therapy for secondary prevention of CAT in most cancer patients [34].

The American Society of Clinical Oncology (ASCO) updated guidelines recommends rivaroxaban, edoxaban and LMWH as the firstchoice options for VTE treatment. However, due to the observed gastrointestinal bleeding risk, NOACs use should be carefully evaluated in patients with gastric cancer. Before starting NOACs, potential drug-drug interactions (DDIs) and avoid their administration with chemotherapy drugs that strongly induce or inhibit P-glycoprotein (P-gp) or CYP3A4 pathways [31].

\section{Guideline Recommendations}

New CHEST Guidelines 2021 are mentioned in Table 3 [35].

\section{NOACS IN AF}

\section{Why are NOACs Chosen over VKAs for the Treatment of AF?}

Meta-analysis of RE-LY (dabigatran), ROCKETAF (rivaroxaban), and ARISTOTLE (apixaban) included 42,411 participants with AF that received NOAC had significantly reduced stroke or systemic embolic events by $19 \%$ compared with warfarin (RR $0.81, p<0.0001$ ), relative risk reduction (RRR) in hemorrhagic stroke by $51 \%$ (RR 0.81, $p<0.0001$ ) and reduction in intracranial hemorrhage by $52 \%$ (RR 0.48 , $p<0.0001)$. Furthermore, NOACs reduced major bleeding by a RRR of $14 \%$. Low-dose NOAC had similar overall reductions in stroke or systemic embolic events compared to warfarin $(1.03, p=0.74)$, and a more favorable bleeding profile $(0.65, p=0.05)$, but significantly more ischemic strokes $(1.28, p=0.045)$. The low-dose NOAC showed a significant reduction in all-cause mortality, similar to the higher-dose regimens [12]. The meta-analysis concluded that NOAC had a favorable risk-benefit profile, compared to warfarin. NOACs significantly reduced stroke, intracranial hemorrhage, and mortality. NOACs had a similar major bleeding, but increased gastrointestinal bleeding, compared to warfarin.

The Italian study showed that the differences between NOAC and VKA were much less when patients treated with VKA were regularly followed by the anticoagulation clinics. These clinics markedly improved management of VTE. Firstly, possible periods of under-anticoagulation were avoided and secondly improving the bridging with a parenteral anticoagulant especially during the first months of treatment was done $[36,37]$. 
Table 3 Recommendations from updated 2021 CHEST Guidelines for VTE [35]

\begin{tabular}{|c|c|c|}
\hline Indication & Recommendation & $\begin{array}{l}\text { Strength of } \\
\text { recommendation }\end{array}$ \\
\hline Cancer-associated VTE & DOACs should be used for the treatment phase of therapy* & Strong \\
\hline $\begin{array}{l}\text { VTE and antiphospholipid } \\
\text { syndrome }\end{array}$ & $\begin{array}{l}\text { Warfarin (target INR 2.5) is recommended over DOAC therapy } \\
\text { during the treatment phase for VTE }\end{array}$ & Weak \\
\hline Treatment-phase anticoagulants & DOACs are recommended over warfarin & Strong \\
\hline \multirow[t]{3}{*}{$\begin{array}{l}\text { Extended-phase therapy (beyond } \\
3 \text { months) for VTE }\end{array}$} & $\begin{array}{l}\text { Extended anticoagulation should be offered to patients with } \\
\text { unprovoked VTE }\end{array}$ & $\begin{array}{l}\text { Strong } \\
\text { Weak }\end{array}$ \\
\hline & $\begin{array}{l}\text { DOAC (low-dose apixaban or rivaroxaban) is recommended } \\
\text { over full doses of these agents }\end{array}$ & Weak \\
\hline & $\begin{array}{l}\text { Aspirin is recommended for patients who are stopping } \\
\text { anticoagulation }\end{array}$ & \\
\hline
\end{tabular}

${ }^{*}$ For patients with luminal gastrointestinal malignancies, apixaban or low molecular weight heparin is preferred to reduce bleeding risk

\#No major or minor transient risk factors. Risk for recurrent VTE, risk for bleeding, and patients' values and preferences should be considered in decisions about extended anticoagulation therapy

\section{Risk Assessment of AF Patients About to Start Anticoagulation Treatment}

Thromboprophylaxis consists of stroke risk assessment and assessing bleeding risk. The 2012 focused update to the European Society of Cardiology (ESC) guidelines recommends stroke risk assessment using the CHA2DS2-VASc score. The HAS-BLED score is the recommended score in the ESC and Canadian guidelines for this purpose. HAS-BLED has been well validated in the past [38]. The assessment of the risk of anticoagulation in patients with AF involves the use of the CHA2DS2VASc, HAS-BLED, and SAMeTT2R scores to evaluate stroke risk, bleeding risk, and likelihood of successful warfarin therapy, respectively. NOACs may be considered where the SAMeTT2R score predicts poor control of anticoagulation with warfarin (Fig. 3).

Individual assessment of stroke risk and risk of bleeding with drug is the first step of deciding about appropriate stroke thromboprophylaxis. Use of risk assessment tools such as $\mathrm{CHA}_{2} \mathrm{DS}_{2}$-VASc and HAS-BLED can help doctors choose antithrombotic strategy. The validated
HAS-BLED allows the clinician to identify bleeding risk factors and to correct those that are modifiable [28]. HAS-BLED is more user friendly and is made up of clinical information that is routinely available before therapy is initiated [39]. Modified $\mathrm{mCHA}_{2} \mathrm{DS}_{2}$-VASc is a validated tool for stroke risk stratification [40].

\section{NOAC Dose for the Treatment of AF}

Table 4 shows the dose of NOACs in AF [42].

\section{Once- or Twice-Daily NOAC Therapy in AF}

A meta-analysis of six RCTs concluded that in Asian patients with AF, NOACs, regardless of dosing regimens, have a similar feature of preserved efficacy with improved safety compared with warfarin. There was no effect modification by dosing regimens in the risk of stroke or systemic embolism across ethnicities (all interaction $p>0.05$ ) [43]. All NOACS (without differences between regimens) showed a $10 \%$ reduction in all-cause mortality when compared with warfarin, seen in a fixed-effects metaanalysis [44]. 


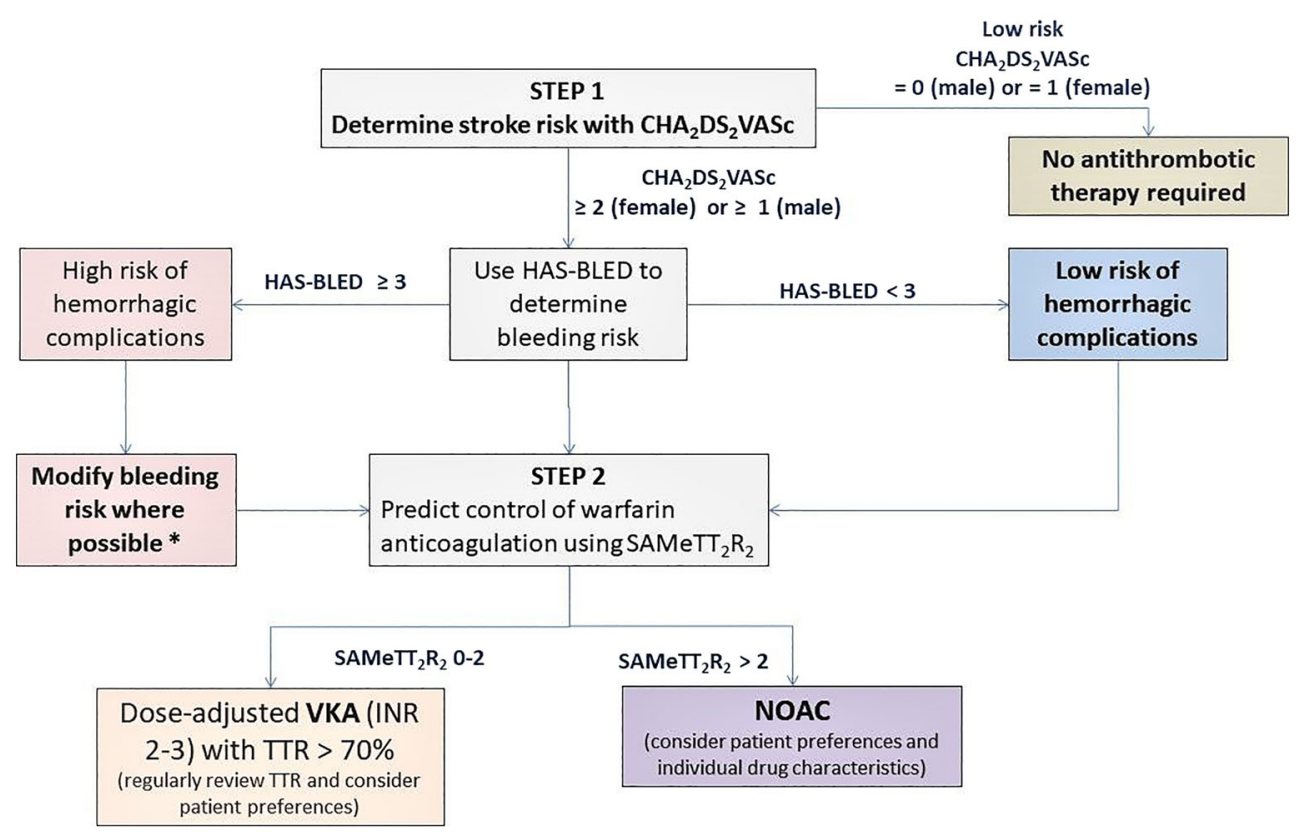

Fig. 3 Selection of stroke-prevention therapies in patients with non-valvular atrial fibrillation (NVAF) and risk factors based on the CHA2DS2-VASc score [41]. ${ }^{*}$ Uncontrolled hypertension, labile INRs, concomitant aspirin/NSAID use, alcohol excess. $V K A$ vitamin $\mathrm{K}$ antagonist, INR international normalized ratio, NSAID non-steroidal anti-inflammatory drug, $O A C$ oral

In a multi-center, cross-sectional study, 2214 subjects with NVAF that took NOAC (once or twice daily) for 3 months showed that though twice-daily dosing of NOACs was associated with decreased adherence in patients, it was not an independent risk factor for bleeding complications [45]. A missed dose can be detrimental for patients, especially if the dose missed is of an oral anticoagulant. NOACs are usually prescribed for a long time, thus simple dosing schedules such as once-daily dosing may benefit patients. Medication adherence to NOACs is crucial to maintain an optimum level of efficacy and safety since compliance and adherence significantly affect outcomes in VTE and AF. Once-daily dosing has the potential to improve rates of stroke prevention in patients with $\mathrm{AF}$ [46]. A recently published meta-analysis does not observe a global difference of efficacy and safety between BD and OD regimens of NOACs in MOS, NVAF, VTE, and ACS [19]. anticoagulant, TTR time in therapeutic range. Antiplatelet therapy with aspirin-clopidogrel or-less effectivelyaspirin monotherapy (consider only in patients who are unwilling or unable to take any form of OAC whether VKA or NOAC)

Rivaroxaban administered once daily would improve medication adherence and patient outcomes, thus leading to long-term benefits in patients with non-valvular AF at risk of stroke [47]. The phase III study, ROCKET-AF validated Rivaroxaban $20 \mathrm{mg}$ OD $(\mathrm{CrCl} \geq 50 \mathrm{ml} / \mathrm{min})$ and $15 \mathrm{mg}$ OD $(\mathrm{CrCl} 30-49 \mathrm{ml} / \mathrm{min})$ in patients with AF had similar efficacy [25]. Bleeding rates of twice-daily Edoxaban were higher than oncedaily groups. Few real-world and retrospective studies observed that patients on once-daily dosing regimen had better adherence and persistence to therapy [48]. In both standard and reduced-dose regimens, edoxaban showed comparable effectiveness and safety compared to rivaroxaban in Korean patients with NVAF. Among four available NOACs, rivaroxaban and edoxaban have the advantage of once-daily administration, allowing convenience and lower pill burden [49]. 
Table 4 Dose of NOACs in AF [26]

\begin{tabular}{|c|c|c|c|c|}
\hline Parameter & Dabigatran & Rivaroxaban & Apixaban & Edoxaban \\
\hline $\begin{array}{c}\text { Standard } \\
\text { dose }\end{array}$ & $150 \mathrm{mg}$ twice daily & $\begin{array}{l}20 \mathrm{mg} \text { once } \\
\text { daily }\end{array}$ & $5 \mathrm{mg}$ twice daily & $60 \mathrm{mg}$ once daily \\
\hline Lower dose & $110 \mathrm{mg}$ twice daily & & & \\
\hline $\begin{array}{l}\text { Reduced } \\
\text { dose }\end{array}$ & & $\begin{array}{l}15 \mathrm{mg} \text { once } \\
\text { daily }\end{array}$ & $2.5 \mathrm{mg}$ twice daily & $30 \mathrm{mg}$ once daily \\
\hline $\begin{array}{l}\text { Dose- } \\
\text { reduction- } \\
\text { criteria }\end{array}$ & $\begin{array}{l}\text { Dabigatran } 110 \mathrm{mg} \\
\text { b.i.d. in patients } \\
\text { with: } \\
\text { Age } \geq 80 \text { years } \\
\text { Concomitant use of } \\
\text { verapamil, or } \\
\text { Increased bleeding } \\
\text { risk }\end{array}$ & $\begin{array}{l}\mathrm{CrCl} \\
15-49 \mathrm{ml} / \\
\min \end{array}$ & $\begin{array}{l}\text { At least } 2 \text { or } 3 \text { criteria: } \\
\text { Age } \geq 80 \text { years } \\
\text { Body weight } \leq 60 \mathrm{~kg} \text {, } \\
\text { or } \\
\text { Serum } \\
\text { creatinine } \geq 1.5 \mathrm{mg} / \\
\text { dl }\end{array}$ & $\begin{array}{l}\text { If any of the following } \\
\mathrm{CrCl} 15-50 \mathrm{ml} / \mathrm{min} \\
\text { Body weight } \leq 60 \mathrm{~kg} \\
\text { Concomitant use of dronedarone, } \\
\text { cyclosporine, erythromycin, or } \\
\text { ketoconazole }\end{array}$ \\
\hline
\end{tabular}

$\mathrm{CrCl}$ creatinine clearance

\section{Duration of NOAC Therapy in AF Patients}

When contemplating the usage and duration of combination antithrombotic therapy in $\mathrm{AF}$ patients who have had an ACS or who are undergoing percutaneous coronary intervention (PCI), the risks of ischemic stroke/systemic embolism, coronary ischemia episodes, and antithrombotic treatment-related bleeding must be carefully considered. Overall, when compared to triple therapy, dual antithrombotic therapy with an OAC (preferably NOAC) and a P2Y12 inhibitor (preferably clopidogrel) is associated with significantly less major bleeding including intracranial hemorrhage (ICH). However, existing evidence suggests that in some AF patients who have recently had an ACS or are having PCI, at least a short course of triple therapy ( $\leq 1$ week) would be desirable in such patients, especially in those at increased risk of ischemic events (Fig. 4) [42].

\section{Secondary Stroke Prevention in AF Patients After Acute Ischemic Stroke}

The 2020 European Society of Cardiology (ESC) guidelines recommend long-term secondary prevention of stroke using oral anticoagulant in patients with AF and an ischemic stroke or transient ischemic attack (TIA), if there is no strict contraindication to OAC use, with a preference for NOACs over VKAs in NOAC-eligible patients [42].

\section{Dual Antiplatelet Therapy (DAPT)}

Contemporary PCI involves the placement of a stent in vast majority of cases. This necessitates pharmacotherapy with dual antiplatelet therapy (DAPT) following stent implantation (Fig. 5; Table 5).

The number of patients undergoing PCI who mandate additional oral anticoagulant therapy has been increasing. It should be noted that the addition of a NOAC increases the likelihood of bleeding while on antiplatelet therapy. The overall risks and benefits for each patient undergoing PCI on NOACs must be assessed and therapy individualized to ensure optimal therapy for each unique clinical situation.

Both pivotal trials (PIONEER AF-PCI trial for rivaroxaban and RE-DUAL trial for dabigatran) reported significantly lower bleeding with the dual antithrombotic regimen compared to triple therapy. However, previous studies showed that triple therapy had a higher risk of bleeding 


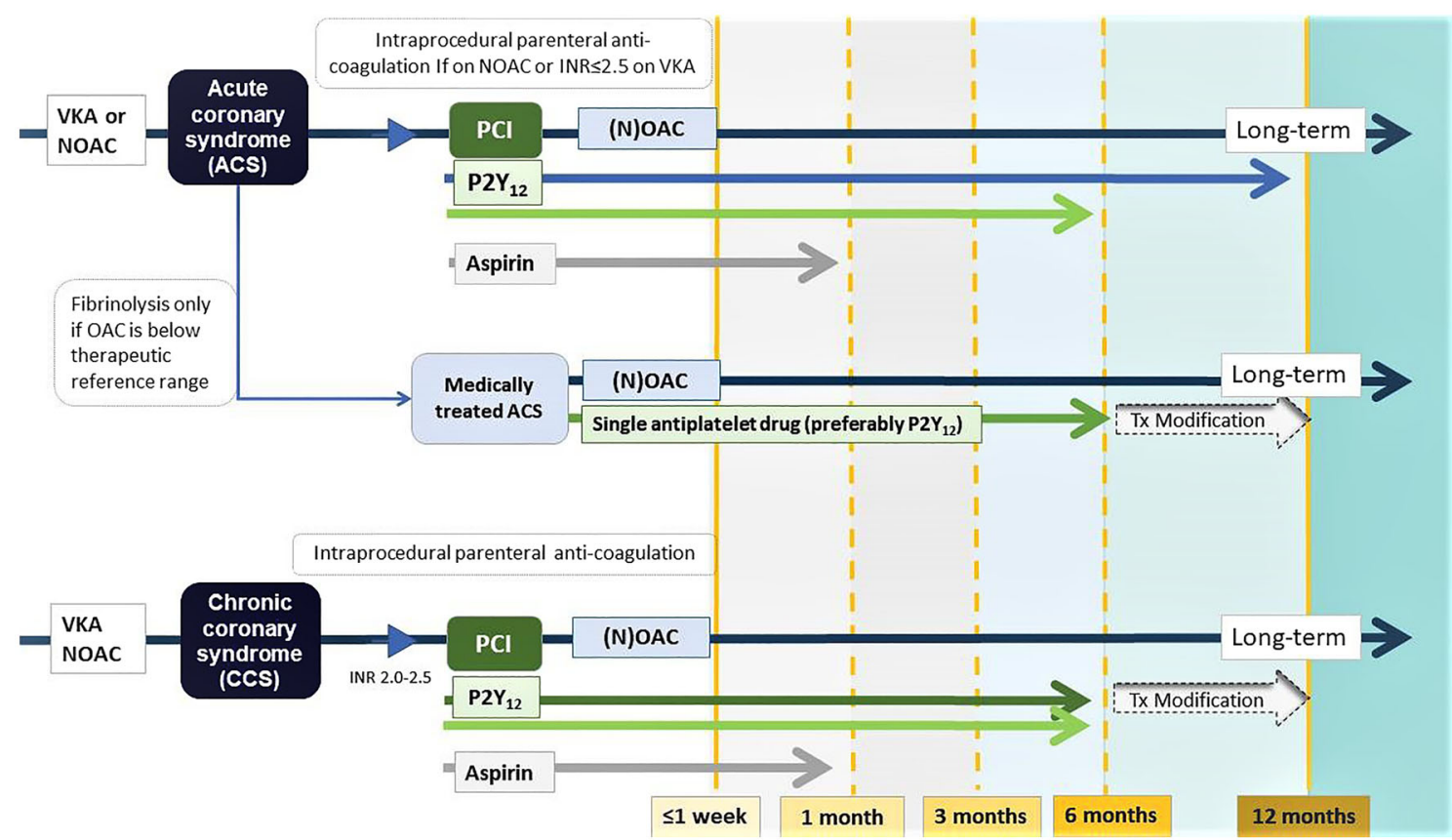

Fig. 4 Post-procedural management of patients with AF and ACS/PCI [42]. Full-outlined arrows-default strategy; dashed arrows-treatment modifications. ACS acute coronary syndromes, $A S A$ acetylsalicylic acid, $C A D$ coronary artery disease, $C C S$ chronic coronary syndromes, $C K D$ chronic kidney disease, DAPT dual antithrombotic therapy, $e G F R$ estimated glomerular filtration rate, $I C H$ intracranial hemorrhage, INR international normalized ratio, $L M W H$ low molecular weight heparin, $M I$

[51]. A recent Danish study showed that AF patients on triple therapy experienced a higher rate of bleeding in comparison with dual therapy or monotherapy [52]. Furthermore, the 2020 ACC expert consensus does not recommend triple therapy for most patients due to increased bleeding risk [53]. The PIONEER AFPCI trial included 2124 subjects with nonvalvular AF treated with PCI. Patients were randomized to receive either low-dose rivaroxaban (15 mg OD) plus P2Y 12 inhibitor (group 1) or very low dose rivaroxaban $(2.5 \mathrm{mg} \mathrm{BD})$ plus DAPT (group 2), or standard therapy with a dose-adjusted vitamin $\mathrm{K}$ antagonist (OD) plus DAPT (group 3). The rates of clinically significant bleeding were lower in the two groups receiving rivaroxaban (15 $\mathrm{mg}$ once daily or $2.5 \mathrm{mg}$ twice daily) than in the group receiving standard therapy $(16.8 \%$ in group $1,18.0 \%$ in myocardial infarction, $N O A C$ non-vitamin $\mathrm{K}$ antagonist oral anticoagulant, $N S A I D$ non-steroidal anti-inflammatory drug, $O A C$ oral anticoagulant, $P A D$ peripheral artery disease, $P C I$ percutaneous coronary intervention, $P P I$ proton-pump inhibitor, STEMI ST-segment elevation myocardial infarction, UFH unfractionated heparin, $V K A$ vitamin $\mathrm{K}$ antagonist

group 2, and $26.7 \%$ in group $3 ; p<0.001$ ). In participants with atrial fibrillation undergoing PCI with the placement of stents, the administration of either low-dose rivaroxaban plus a P2Y12 inhibitor for 12 months or very low dose rivaroxaban plus DAPT for 1,6 , or 12 months was associated with a lower rate of clinically significant bleeding than was standard therapy with a vitamin $\mathrm{K}$ antagonist plus DAPT for 1, 6 , or 12 months [54].

In the RE-DUAL trial with 2725 subjects, patients were randomized to receive either dabigatran $110 \mathrm{mg}$ or $150 \mathrm{mg}$ with P2Y12 inhibitor, or warfarin with $\mathrm{P}_{2} \mathrm{Y}_{12}$ inhibitor and aspirin. In patients with $\mathrm{AF}$ who had undergone PCI, the benefits of both dabigatran doses (110 and $150 \mathrm{mg}$ ) dual therapy were comparable to warfarin triple therapy for the composite endpoint of death, myocardial infarction, stroke, 


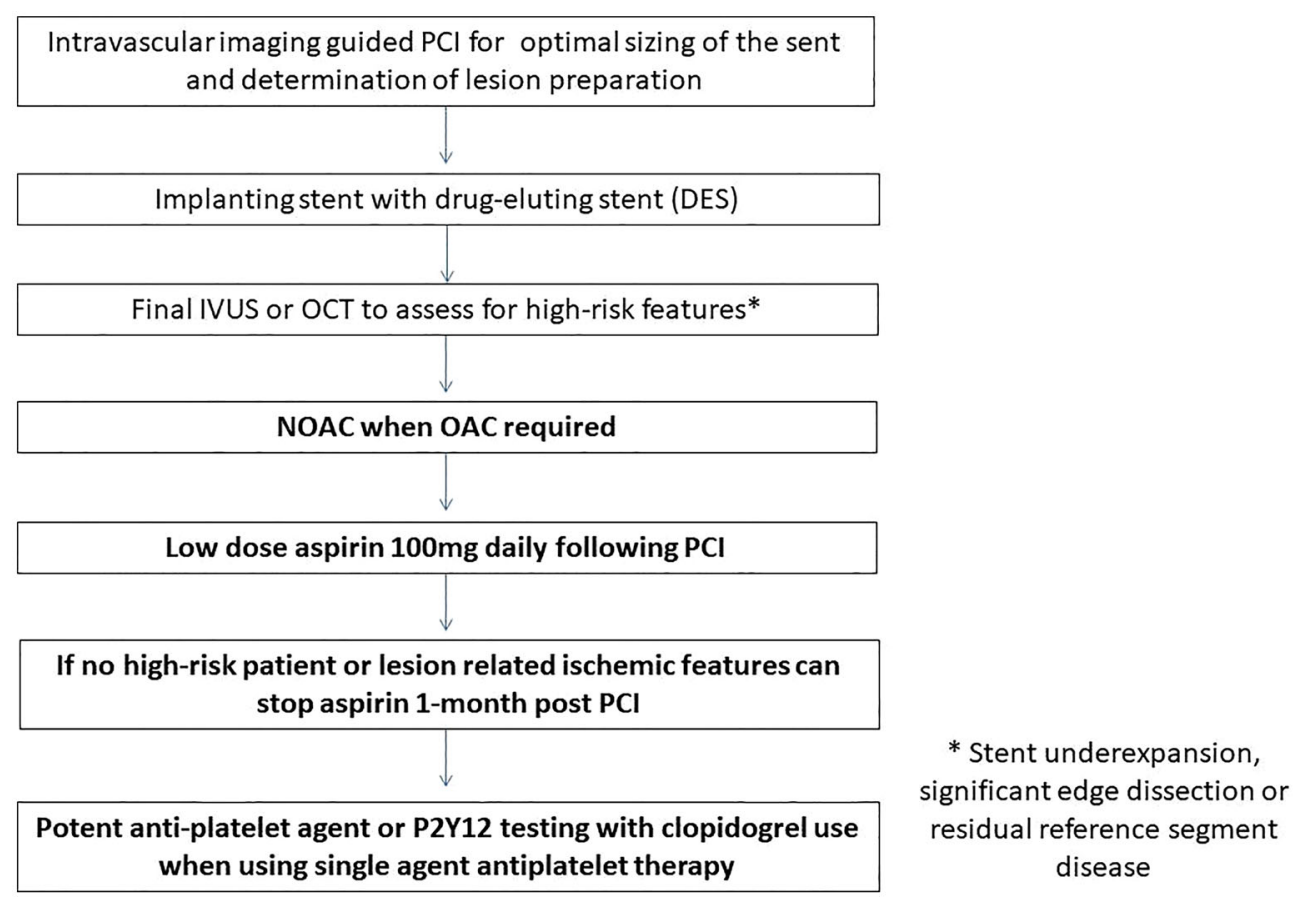

Fig. 5 Stepwise approach to initiate NOAC while on DAPT [50]. *Stent under-expansion, significant edge dissection or residual reference segment disease. DAPT dual antiplatelet therapy, $D E S$ drug-eluting stent, IVUS intravascular ultrasound, $N O A C$ novel oral anticoagulant, $O A C$ oral anticoagulant, $O C T$ optical coherence tomography, $P C I$ percutaneous coronary intervention

Table 5 Recommendation by 2020 ESC guidelines for DAPT [42]

\begin{tabular}{lll}
\hline Recommendation & $\begin{array}{l}\text { Class of } \\
\text { recommendation }\end{array}$ & $\begin{array}{l}\text { Level of } \\
\text { evidence }\end{array}$ \\
\hline $\begin{array}{l}\text { In AF patients eligible for NOACs, it is recommended to use a NOAC in preference to } \\
\text { I }\end{array}$ & $\mathrm{A}$ \\
a VKA in combination with antiplatelet therapy & $\mathrm{B}$ \\
$\begin{array}{l}\text { In patients at high bleeding risk (HAS-BLED } \geq 3 \text { ), rivaroxaban } 15 \mathrm{mg} \text { OD should be IIa } \\
\begin{array}{l}\text { considered in preference to rivaroxaban } 20 \mathrm{mg} \text { OD for the duration of concomitant } \\
\text { single or DAPT to mitigate bleeding risk }\end{array}\end{array}$ \\
$\begin{array}{l}\text { In patients at high bleeding risk (HAS-BLED } \geq 3 \text { ), dabigatran } 110 \mathrm{mg} \text { b.i.d. should be IIa } \\
\begin{array}{l}\text { considered in preference to dabigatran } 150 \mathrm{mg} \text { b.i.d. for the duration of concomitant } \\
\text { single or DAPT to mitigate bleeding risk }\end{array}\end{array}$ & $\mathrm{B}$ \\
\hline
\end{tabular}

systemic embolism, or unplanned revascularization, with minor variations across all four subgroups (all interactions $p$ values $>0.10$ ) [55]. DAPT is associated with reduced ischemic events including stent thrombosis, myocardial infarction, and stroke following PCI [42].

\section{Special Population}

\section{$A F$ and $C K D$}

Dosing of NOACs in patients with AF with CKD is mentioned in Table 6 [42]. 
Table 6 Dosing of NOACs in patients with AF with CKD [42]

\begin{tabular}{|c|c|c|c|c|c|}
\hline $\begin{array}{l}\text { CKD } \\
\text { stage }\end{array}$ & eGFR & Rivaroxaban & Apixaban & Dabigatran & Edoxaban \\
\hline Stage 1 & $\begin{array}{c}>95 \mathrm{ml} / \\
\min \end{array}$ & $20 \mathrm{mg}$ OD & $\begin{array}{l}2.5 \mathrm{mg} \mathrm{BD} \text { or } 5 \mathrm{mg} \\
\mathrm{BD}\end{array}$ & $150 \mathrm{mg} \mathrm{BD}$ & $60 \mathrm{mg}^{\#}$ \\
\hline Stage 2 & $\begin{array}{l}50-94 \mathrm{ml} / \\
\min \end{array}$ & & & & $60 \mathrm{mg}$ \\
\hline Stage 3 & $\begin{array}{l}30-49 \mathrm{ml} / \\
\min \end{array}$ & $15 \mathrm{mg}$ OD & & $\begin{array}{l}150 \mathrm{mg} \mathrm{BD} \text { or } 110 \mathrm{mg} \mathrm{BD} \text { (high bleeding } \\
\text { risk) }\end{array}$ & $30 \mathrm{mg}$ \\
\hline Stage 4 & $\begin{array}{l}15-29 \mathrm{ml} / \\
\min \end{array}$ & $15 \mathrm{mg} \mathrm{OD}^{*}$ & 2.5 mg BD* & DO NOT USE & $30 \mathrm{mg}^{*}$ \\
\hline Stage 5 & Dialysis & \multicolumn{4}{|c|}{ DO NOT USE } \\
\hline
\end{tabular}

Independently of $\mathrm{AF}, \mathrm{CKD}$ is a prothrombotic and prohemorrhagic condition and $\mathrm{AF}$ may accelerate CKD progression. In AF patients, renal function can deteriorate over time, and worsening $\mathrm{CrCl}$ is a better independent predictor of ischemic stroke/systemic embolism and bleeding than renal impairment per se [56]. Choose NOAC based on (a) renal function (CrCl), (b) drug pharmacokinetics, (c) patient's characteristics.

All four NOACs produced comparable results in the primary efficacy endpoints (stroke and SEE) and the primary safety endpoint (major bleeding) across different stages of renal function. The only exception was found in the ARISTOTLE trial. Apixaban seems to produce less bleeding compared to warfarin in patients with an eGFR $<50 \mathrm{ml} / \mathrm{min}$ than in those with a higher eGFR ( $p$ for interaction 0.030). In patients with mild-to-moderate $\mathrm{CKD}(\mathrm{CrCl}$ $30-49 \mathrm{ml} / \mathrm{min})$, the safety and efficacy of NOACs versus warfarin were consistent with patients without CKD in landmark NOAC trials, hence the same considerations for stroke risk assessment and choice of oral anticoagulant may apply. Clearance of NOACs from the body is dependent on renal function, which should be assessed regularly. Of the oral factor Xa drugs, rivaroxaban has $35 \%$ renal clearance while apixaban has $27 \%$ renal clearance and edoxaban has 50\% renal excretion. The renal clearance of warfarin is $<1 \%$ and hence it may be safe for patients with severe CKD [57].

Patients with $\mathrm{CrCl} 15-29 \mathrm{ml} / \mathrm{min}$ : RCTderived data on the effect of VKA or NOACs are lacking. Data from observational studies conclude possible bleeding risk reduction in patients with ESRD taking a NOAC compared with VKA. There is no solid evidence for a reduction in embolic events with either NOACs or VKAs. For patients with AF after kidney transplantation, there is no data on OAC use in such patients. The prescription and dosing of NOACs should be guided by the estimated glomerular filtration rate of the transplanted kidney and taking into account potential interactions with concomitant medication. NOACs (except apixaban) should be avoided in such patients, while VKAs may be preferable [58].

\section{The Elderly and Frail with AF}

NOACs appear to have a better overall risk-benefit profile compared with warfarin [42]. An Indian consensus recommended that age should not be a limiting factor for use of NOACs. In AF trials, NOACs were more effective than conventional therapy in prevention of stroke or systemic embolism in an elderly population with AF [28]. In one study, anticoagulation therapy significantly increased long-term 
overall survival (OS) without increasing risk of clinically relevant bleeding in patients with $\mathrm{AF}$ and sinus rhythm (SR) [59]. In another cohort study with patients $\geq 75$ years $(30,401)$, standard and reduced dose NOACs had similar risks of stroke as warfarin and lower or similar risks of bleeding in patients with AF. Thus, NOACs seem to be a safe oral anticoagulant in elderly patients [60].

\section{NOAC IN PATIENTS WITH HEPATIC IMPAIRMENT AND AF/VTE}

Like other disease states noted above, patients with hepatic impairment are at increased risk of bleeding complications and thrombotic events. Alterations in hepatic function affect NOAC biotransformation to varying extents. Restrictions for the use of NOACs in patients with hepatic impairment are based on the Child-Pugh classification system and exclusion criteria applied in pivotal trials (Table 7) [61].

\section{NOAC IN PATIENTS WITH OBESITY AND AF/VTE}

\section{Obesity and AF}

While obesity is an independent risk factor for $\mathrm{AF}$, the presence of both comorbidities is becoming common. The pharmacokinetics of anticoagulants is altered in obese patients resulting in subtherapeutic serum drug concentrations causing suboptimal efficacy. Drugs with long half-lives and large volume of distribution $\left(V_{d}\right)$ get affected by higher BMI while drugs with shorter $t_{1 / 2}$ and small $V_{d}$ may be less affected by adiposity. In obese patients, the efficacy of NOACs over warfarin is less defined and has the potential for causing subtherapeutic anticoagulation and lower efficacy. The subgroup analysis of RE-LY, ENGAGE-AF TIMI 48, ARISTOTLE, and ROCKET-AF trial showed that NOAC has similar efficacy compared to warfarin for reducing stroke in obese patients, but major bleeding was similar or higher with NOACs [62]. Results of NOAC in AF and obesity trials are mentioned in Table 8.

In a retrospective analysis, in patients with NVAF, NOACs had better effectiveness and safety compared to warfarin across all BMI categories (underweight and morbidly obese patients) [63]. In a meta-analysis, NOAC was not statistically different from VKA in reducing stroke/SE with RR of 0.85 in morbidly obese patients with atrial fibrillation. Also, major bleeding risk was lower in the NOAC groups with RR of 0.62 . Thus, using NOACs in morbidly obese patients may be considered on a case-by-case basis, but more studies are needed to make a robust recommendation [64]. Evidence suggests that NOACs are as effective, if not superior, to warfarin for preventing stroke in obese patients with AF.

\section{Obesity and VTE}

In obese patients with acute VTE, there was no differences VTE recurrence $(6.5$ vs. $6.4 \%$, $p=0.63)$, recurrence of $\mathrm{PE}(3.7$ vs. $3.8 \%$, $p=0.94$ ), or DVT (3 vs. $3.5 \%, p=0.56$ ) between treatment with NOACs and warfarin. Bleeding was similar for both, NOAC and warfarin groups (1.7 vs. $1.2 \%, p=0.31$ ) [65]. Another observational study demonstrated NOAC to be effective and safe in morbid obese patients even after intermediate- or high-risk PE [65].

Recommendations from The International Committee on Thrombosis and Haemostasis (ISTH) Scientific and Standardization

Table 7 NOAC in different stages of hepatic impairment [61]

\begin{tabular}{lllll}
\hline Child-Pugh category & Rivaroxaban & Apixaban & Dabigatran & Edoxaban \\
\hline A & No dose reduction & No dose reduction & No dose reduction & No dose reduction \\
B & Contraindicated & Use with caution & Use with caution & Use with caution \\
C & & Contraindicated & Contraindicated & Contraindicated \\
\hline
\end{tabular}


Table 8 Clinical trials of AF and obesity

\begin{tabular}{|c|c|c|c|c|c|c|}
\hline $\begin{array}{l}\text { Landmark } \\
\text { trial }\end{array}$ & $\begin{array}{l}\text { Patient } \\
\text { characteristics }\end{array}$ & $\begin{array}{l}\text { No. of enrolled } \\
\text { obese patients }\end{array}$ & Results & & & \\
\hline \multirow[t]{4}{*}{ RE-LY } & \multirow{2}{*}{$\underset{\mathrm{m}^{2}}{\mathrm{BMI}} \geq 36 \mathrm{~kg} /$} & 1787 & \multirow[t]{2}{*}{ Outcome } & \multirow{2}{*}{$\begin{array}{c}\text { Dabigatran } \\
110 \mathrm{mg}\end{array}$} & \multirow{2}{*}{$\begin{array}{c}\text { Dabigatran } \\
150 \mathrm{mg}\end{array}$} & \multirow[t]{2}{*}{ Warfarin } \\
\hline & & 3099 & & & & \\
\hline & \multirow[t]{2}{*}{ Weight $>100 \mathrm{~kg}$} & Total & Stroke/SEE & $1.2 \%$ & $0.9 \%$ & $1.3 \%$ \\
\hline & & $N=18,114$ & Major bleeding & $3 \%$ & $4.4 \%$ & $3.7 \%$ \\
\hline \multirow{6}{*}{$\begin{array}{l}\text { ROCKET- } \\
\text { AF }\end{array}$} & \multirow{2}{*}{$\underset{\mathrm{m}^{2}}{\mathrm{BMI}} \geq 30 \mathrm{~kg} /$} & 5206 & \multirow[t]{2}{*}{ Outcome } & \multirow{2}{*}{$\begin{array}{l}\text { Obese } \\
\text { subgroup }\end{array}$} & \multirow{2}{*}{$\begin{array}{l}\text { Nonobese } \\
\text { subgroup }\end{array}$} & \\
\hline & & 1898 & & & & \\
\hline & \multirow{4}{*}{$\underset{\mathrm{m}^{2}}{\mathrm{BMI}} \geq 35 \mathrm{~kg} /$} & Total & Stroke/SEE & $1.88 \%$ & $2.93 \%$ & HR 0.65 \\
\hline & & $N=18,201$ & Major or nonmajor & $14.56 \%$ & $15.79 \%$ & HR 0.94 \\
\hline & & & clinically relevant & & & \\
\hline & & & bleeding & & & \\
\hline \multirow[t]{3}{*}{ ARISTOTLE } & \multirow{2}{*}{$\begin{aligned} \mathrm{BMI} & \geq 30 \mathrm{~kg} / \\
\mathrm{m}^{2} & \end{aligned}$} & 7159 & Outcome & Apixaban & \multicolumn{2}{|l|}{ Warfarin } \\
\hline & & 982 & Stroke/SEE & $0.97 \%$ & $1.28 \%$ & HR 0.76 \\
\hline & Weight $>120 \mathrm{~kg}$ & $\begin{array}{l}\text { Total } \\
\qquad N=18,201\end{array}$ & Major bleeding & $2.12 \%$ & $2.51 \%$ & HR 0.84 \\
\hline \multirow{5}{*}{$\begin{array}{l}\text { ENGAGE } \\
\text { TIMI }\end{array}$} & \multirow{2}{*}{$\begin{aligned} \mathrm{BMI} & \geq 30 \mathrm{~kg} / \\
\mathrm{m}^{2} & \end{aligned}$} & 8457 & \multirow[t]{3}{*}{ Outcome } & \multirow{3}{*}{$\begin{array}{c}\text { Normal } \\
\text { BMI }\end{array}$} & \multirow{3}{*}{$\begin{array}{r}\text { Severely } \\
\text { obese }\end{array}$} & \multirow{3}{*}{$\begin{array}{l}\text { Very } \\
\text { severely } \\
\text { obese }\end{array}$} \\
\hline & & 1149 & & & & \\
\hline & $\mathrm{BMI}>40 \mathrm{~kg} / \mathrm{m}^{2}$ & 148 & & & & \\
\hline & \multirow[t]{2}{*}{$\mathrm{BMI}>50 \mathrm{~kg} / \mathrm{m}^{2}$} & Total & Stroke/SEE & $2.3 \%$ & HR 0.68 & HR 0.54 \\
\hline & & $N=21,105$ & Major bleeding & $2.9 \%$ & HR 1.18 & HR 1.28 \\
\hline
\end{tabular}

$B M I$ body mass index, $S E E$ systemic embolic events

Committee (SSC) Subcommittee on Control of Anticoagulation (2021) recommends the use of any NOAC in patients with BMI up to $40 \mathrm{~kg} / \mathrm{m}^{2}$ or weight $120 \mathrm{~kg}$ [66]. For patients with $\mathrm{BMI}>40 \mathrm{~kg} / \mathrm{m}^{2}$ or weight $>120 \mathrm{~kg}$, the guideline recommend that the individual NOACs should be used as mentioned in Table 9 .

A meta-analysis comprising real-world observational data concludes that the use of NOACs in morbidly obese patients (bodyweight of $>120 \mathrm{~kg}$ or BMI $>40 \mathrm{~kg} / \mathrm{m}^{2}$ ) is effective and safe. It supports the current practice of using NOAC analogs as an alternative to warfarin in this cohort of patients [67].

\section{HOW TO CHOOSE BETWEEN NOACS}

Since there are no head-to-head comparisons of NOACs, it is extremely difficult to provide definitive recommendations on choice of NOAC. Thus, patient characteristics, drug tolerability, and cost may be considered while selecting a NOAC for a specific patient. Risk of ischemic stroke, bleeding, history of stroke, gastrointestinal (GI) upset, past GI bleed and renal impairment are a few of the factors that determine the choice of NOAC (Table 10) [68]. 
Table 9 Recommendations for use of NOAC in obese patients [66]

\begin{tabular}{ll}
\hline Indication & Recommendation \\
\hline Treatment of VTE & Standard doses of rivaroxaban or apixaban are among appropriate anticoagulant \\
& options regardless of high BMI and weight \\
& Fewer supportive data exist for apixaban than rivaroxaban \\
& VKA, weight-based LMWH (per manufacturers' recommendations), and \\
& fondaparinux are also options \\
& Not to use dabigatran, edoxaban, or betrixaban given unconvincing data for \\
& dabigatran, and lack of clinical or PK/PD data for edoxaban and betrixaban \\
& Standard doses of rivaroxaban or apixaban are among appropriate anticoagulant \\
Primary prevention of VTE & options regardless of high BMI and weight \\
Not to use dabigatran, edoxaban, or betrixaban given unconvincing data for & dabigatran, and lack of clinical or PK/PD data for edoxaban and betrixaban \\
Post bariatric surgery - treatment or & Initiate patients on parenteral anticoagulation in the early postsurgical phase \\
prevention of VTE & Not to use DOAC (because of concerns of decreased absorption) \\
& Switching to VKA or DOAC may be considered after at least 4 weeks of parenteral \\
treatment, and if so, suggest obtaining a DOAC trough level to check for drug \\
absorption and bioavailability
\end{tabular}

\section{SWITCHING BETWEEN NOACS}

It is not uncommon to switch from one anticoagulant to another. The decision to switch and type of anticoagulant depends on factors such as cost, comorbidity, patient preference, hospitalization, thrombotic complications, bleeding complications, or procedures [61]. The scenarios that exist are explained in Table 11.

Monitoring of anticoagulant effect is important before, during, and after switching. INR should be measured just before the NOAC dosing and re-tested $24 \mathrm{~h}$ after the last NOAC dose (i.e., sole warfarin therapy) to assure adequate anticoagulation. Since NOACs may have an additional influence on INR during the overlap phase, closely monitor INR within the first month until stable values are attained (i.e., three consecutive measurements between 2 and 3) [69].

\section{PERIOPERATIVE MANAGEMENT OF PATIENTS ON ANTICOAGULANTS}

The clinicians must assess the patient's thromboembolic risk:

- Bleeding risks: (a) patient-specific (b) procedure-specific.

- Understand the NOAC's pharmacological properties.

- Assess the patients' renal function.

- Determine the timing of the anticoagulant interruption.

- Determine whether to use bridging anticoagulation [70].

\section{NOAC Interruption}

A patient-centered approach to NOAC interruption that is anchored on the procedure-related bleed risk, NOAC type, and patient renal function is shown in Fig. 6. 
Table 10 Factors to consider when choosing an oral anticoagulant [68]

\begin{tabular}{|c|c|c|}
\hline Specific patient characteristics & Considerations & $\begin{array}{l}\text { Choice of } \\
\text { NOAC }\end{array}$ \\
\hline $\begin{array}{l}\text { High risk of bleeding, e.g., HAS- } \\
\text { BLED } \geq 3\end{array}$ & Consider agent/dose with the lowest incidence of bleeding & $\begin{array}{l}\text { Dabigatran } \\
110 \mathrm{mg} \\
\text { Apixaban }\end{array}$ \\
\hline Previous GI bleeding or high risk & Consider agent the lowest reported incidence of GI bleed & Apixaban \\
\hline $\begin{array}{l}\text { High risk of ischemic stroke, low } \\
\text { bleeding risk }\end{array}$ & Consider agent/dose with the best reduction of ischemic stroke & $\begin{array}{l}\text { Dabigatran } \\
150 \mathrm{mg}\end{array}$ \\
\hline Previous stroke (secondary prevention) & $\begin{array}{l}\text { Consider best investigated agent or greatest reduction of } \\
\text { secondary stroke }\end{array}$ & $\begin{array}{l}\text { Rivaroxaban } \\
\text { Apixaban }\end{array}$ \\
\hline $\begin{array}{l}\text { CAD, previous MI or high risk for } \\
\text { ACS/MI }\end{array}$ & Consider agent with a positive effect in ACS & Rivaroxaban \\
\hline Renal impairment & Consider agent less dependent on renal function & $\begin{array}{l}\text { Apixaban } \\
\text { Rivaroxaban }\end{array}$ \\
\hline GI upset/disorders & Consider agent/dose with no reported GI effects & Apixaban \\
\hline Patient preference & Consider once daily formulation & Rivaroxaban \\
\hline
\end{tabular}

Doses may need to be adjusted for interactions, weight, and co-morbidities

$A C S$ acute coronary syndrome, $A F$ atrial fibrillation, CAD coronary artery disease, GI gastrointestinal, HAS-BLED hypertension, abnormal renal/liver function (1 point each), stroke, bleeding history or predisposition, labile international normalized ratio, elderly ( $\geq 65$ years), drugs/alcohol concomitantly (1 point each), MI myocardial infarction

The Perioperative Anticoagulation Use for Surgery Evaluation (PAUSE) cohort study included patients with AF who had NOAC interruption for elective surgery/procedure. The PAUSE study had the following approach: 1 full day off NOAC if low bleed risk; 2 full days off NOAC if high bleed risk (in addition to no NOAC intake on the procedure day. The postprocedure resumption of NOAC mirrored preprocedure management in that the NOAC was resumed after 1 day (at least $24 \mathrm{~h}$ ) after a low bleed risk procedure, and resumed after 2 days after a high bleed risk procedure. The initiation of a prophylactic dose anticoagulant (LMWH or NOAC) was considered in patients at high bleeding risk in whom a delay of full-dose anticoagulation was warranted. Patients that had a simple standardized perioperative management strategy without heparin bridging or measurement of coagulation function had low rates of major bleeding and arterial thromboembolism [71]. NOAC interruption and restarting regimen during elective procedures is mentioned in Table 12 [61].

\section{Does NOACs Require Bridging Anticoagulant?}

NOACs do not require parenteral overlapping or "bridging" anticoagulants peri-procedurally. NOACs (dabigatran, rivaroxaban, apixaban, edoxaban) have relatively shorter time-to-onset and half-lives (about $12 \mathrm{~h}$ ) and are easier to discontinue and resume rapidly [70]. Hence, $\mathrm{LMWH} /$ heparin bridge was used as a bridging anticoagulant in RE-COVER and RE-COVER II trials, whereas no bridging anticoagulant was used in rivaroxaban trials (EINSTEIN PE, EINSTEIN DVT), apixaban (AMPLIFY), and edoxaban trial (Hokusai-VTE). The rapid offset and 
Table 11 Switching between NOACs and other anticoagulants [61]

\begin{tabular}{|c|c|c|}
\hline From & To & Action \\
\hline VKA & NOAC & $\begin{array}{l}\text { Stop VKA and start NOAC once INR is }<2 \text { or lower INR limit of the therapeutic } \\
\text { range }\end{array}$ \\
\hline Dabigatran & VKA & $\begin{array}{l}\mathrm{CrCl}>50 \mathrm{ml} / \mathrm{min}: \text { start VKA and stop dabigatran } 3 \text { days later } \\
\mathrm{CrCl} 31-50 \mathrm{ml} / \mathrm{min}: \text { start VKA and stop dabigatran } 2 \text { days later } \\
\mathrm{CrCl} 15-30 \mathrm{ml} / \mathrm{min} \text { : start VKA and stop dabigatran } 1 \text { day later }\end{array}$ \\
\hline Rivaroxaban & VKA & Start VKA and stop NOAC 3 days later \\
\hline Apixaban & & $\begin{array}{l}\text { OR } \\
\text { For continuous anticoagulation: Stop NOAC and start LMWH and VKA at the } \\
\text { time NOAC would have been due, then stop LMWH when INR is within the } \\
\text { therapeutic range }\end{array}$ \\
\hline Edoxaban & & $\begin{array}{l}\text { Start VKA and stop NOAC } 3 \text { days later } \\
\text { OR } \\
\text { For continuous anticoagulation: } \\
\text { For } 60 \mathrm{mg} \text { dose: reduce: reduce dose to } 30 \mathrm{mg} \text { and start warfarin concomitantly. Stop } \\
\text { edoxaban when INR }>2 \\
\text { For } 30 \mathrm{mg} \text { dose: reduce dose to } 15 \mathrm{mg} \text { and start warfarin concomitantly. Stop } \\
\text { edoxaban when INR }>2\end{array}$ \\
\hline Betrixaban & VKA & Start VKA and stop NOAC when INR $>$ lower limit of the therapeutic range \\
\hline NOAC & NOAC & $\begin{array}{l}\text { Stop the current NOAC regimen and begin the new NOAC agent at the time the } \\
\text { next dose of NOAC is due }\end{array}$ \\
\hline NOAC & $\begin{array}{l}\text { Parenteral } \\
\text { anticoagulant }\end{array}$ & $\begin{array}{l}\text { Stop NOAC and start parenteral anticoagulation at the same time that the next dose } \\
\text { of NOAC would have been given }\end{array}$ \\
\hline $\begin{array}{l}\text { Parenteral } \\
\text { anticoagulant }\end{array}$ & NOAC & $\begin{array}{l}\text { Intravenous: Start NOAC } 0 \text { to } 2 \mathrm{~h} \text { after stopping UFH } \\
\text { Subcutaneous: Stop LMWH and start NOAC at the same time that the next dose of } \\
\text { LMWH would have been given }\end{array}$ \\
\hline
\end{tabular}

$\mathrm{CrCl}$ creatinine clearance, $I N R$ international normalized ratio, $L M W H$ low molecular weight heparin, $V K A$ vitamin $\mathrm{K}$ antagonist, UFH unfractionated heparin

onset of rivaroxaban negate the need for bridging anticoagulation.

\section{Restarting NOAC Post-procedure}

Restarted 2 days after a high bleeding risk procedure and restarted 1 day after a low/moderate bleeding risk procedure.
Since the anticoagulant effect of NOACs peaks within a few hours, it is safe to wait for 24-72 $\mathrm{h}$ post-procedure before starting the full dose. The restarting dose will be similar to the pre-op dose. Administer a parenteral anticoagulant (low-dose LMW heparin or fondaparinux) regimen (for example enoxaparin $40 \mathrm{mg}$ daily) until the NOAC is resumed (if there is an increased risk of VTE). Dosage adjustment is not 


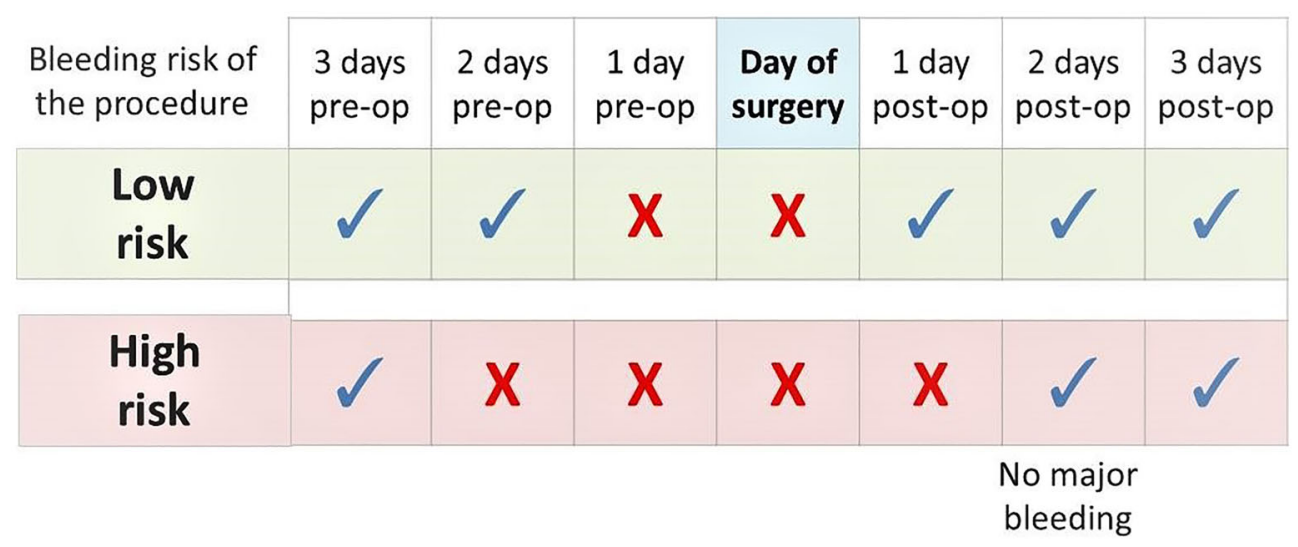

Fig. 6 Timing for interruption of a NOAC before and after elective surgery [71]. ${ }^{*}$ Regular NOAC dose. Note: $\boldsymbol{\sim}$ indicates continue NOAC; $\mathbf{x}$ indicates stopping NOAC

required in patients with moderately impaired kidney function ( $\mathrm{CrCl} 30-50 \mathrm{ml} / \mathrm{min}$ ) [72].

\section{ANTIDOTES OR REVERSIBILITY AGENTS: ARE THEY NEEDED?}

Reversal agents are indicated in patients with major bleed. Non-major/minor bleed-reversal agents not required, and withholding the next NOAC doses is sufficient. The choice of NOAC should not be based on the availability of its respective reversal agents.

Anticoagulant reversal is a critical step in the management of patients with life-threatening bleeding who are taking an anticoagulant. A specific antidote or reversal agent may be considered in severe or life-threatening bleeding in patients receiving NOAC (Fig. 7). There are two types of reversal agents-non-specific and specific reversal agents. FDA-approved reversal agents for NOACs are idarucizumab for dabigatran and andexanet alfa for apixaban and rivaroxaban. Their higher cost and limited availability remain a concern (Table 13; Fig. 8) [72]. A larger amount of clinical data on reversal agents should be available with their increased usage.

\section{DOSING ERRORS}

In case of missed dose, the forgotten dose can be taken up to $6 \mathrm{~h}$ or up to $12 \mathrm{~h}$ after the scheduled intake for a $\mathrm{BD}$ or $\mathrm{OD}$ regimen, respectively. If this is not possible, the dose should be skipped, and the next scheduled dose taken. In case of a double dose on a $\mathrm{BD}$ regimen, the next planned dose can be skipped and restarted BD after $24 \mathrm{~h}$ while in OD dosing, a normal regimen can be continued. In case of overdose, dabigatran can be removed via dialysis. Rivaroxaban and apixaban are not dialyzable, and hence use reversal agents [73].

\section{UNDERDOSING}

Elderly patients with AF should be prescribed anticoagulant therapy, unless contraindicated. Though, the is risk of bleeding is higher in the elderly, it is dependent on a patient's characteristics and not on whether the patient is receiving anticoagulant or not. The bleeding risk should be minimized rather than contraindicating or underdosing the anticoagulant. Various studies indicate that inappropriate prescription of NOACs is not uncommon, especially underdosing [74]. In the SAGE-AF study, underdosing of NOACs was more common than overdosing. Factors that influence prescription of guideline-nonadherent doses may be old age, 
Table 12 When to interrupt and restart NOAC therapy during elective procedures [61]

\begin{tabular}{|c|c|c|c|c|c|}
\hline Bleeding risk of the procedure & Parameter & Rivaroxaban & Apixaban & Dabigatran & Edoxaban \\
\hline \multirow[t]{3}{*}{ Minor } & \multicolumn{5}{|c|}{ Recommended to not stop in most minor surgical procedures } \\
\hline & STOP & \multicolumn{4}{|c|}{$12-24 \mathrm{~h}$ before procedure } \\
\hline & RESTART & \multicolumn{4}{|c|}{$6 \mathrm{~h}$ after intervention } \\
\hline \multirow[t]{7}{*}{ Low risk } & STOP & \multicolumn{4}{|c|}{$24-96 \mathrm{~h}$ before procedure } \\
\hline & $\mathrm{CrCl} \geq 80 \mathrm{ml} / \mathrm{min}$ & $\mathrm{STOP} \geq 24$ & $\mathrm{STOP} \geq 24$ & STOP $\geq 24$ & STOP $\geq 24$ \\
\hline & $\mathrm{CrCl} \leq 50-79 \mathrm{ml} / \mathrm{min}$ & $\mathrm{STOP} \geq 24$ & $\mathrm{STOP} \geq 24$ & STOP $\geq 36$ & $\mathrm{STOP} \geq 24$ \\
\hline & $\mathrm{CrCl} \leq 30-49 \mathrm{ml} / \mathrm{min}$ & STOP $\geq 24$ & STOP $\geq 24$ & STOP $\geq 48$ & STOP $\geq 24$ \\
\hline & $\mathrm{CrCl} \leq 15-29 \mathrm{ml} / \mathrm{min}$ & STOP $\geq 36$ & $\mathrm{STOP} \geq 36$ & Not indicated & $\mathrm{STOP} \geq 36$ \\
\hline & $\mathrm{CrCl} \leq 15 \mathrm{ml} / \mathrm{min}$ & \multicolumn{4}{|c|}{$\begin{array}{l}\text { Consider measuring drug activity to determine absence of drug } \\
\text { effect }\end{array}$} \\
\hline & RESTART & \multicolumn{4}{|c|}{$\geq 24 \mathrm{~h}$ after intervention } \\
\hline \multirow[t]{7}{*}{ High risk } & STOP & \multicolumn{4}{|c|}{$48-96 \mathrm{~h}$ before procedure } \\
\hline & $\mathrm{CrCl} \geq 80 \mathrm{ml} / \mathrm{min}$ & STOP $\geq 48$ & STOP $\geq 48$ & STOP $\geq 48$ & STOP $\geq 48$ \\
\hline & $\mathrm{CrCl} \leq 50-79 \mathrm{ml} / \mathrm{min}$ & $\mathrm{STOP} \geq 48$ & $\mathrm{STOP} \geq 48$ & $\mathrm{STOP} \geq 72$ & $\mathrm{STOP} \geq 48$ \\
\hline & $\mathrm{CrCl} \leq 30-49 \mathrm{ml} / \mathrm{min}$ & $\mathrm{STOP} \geq 48$ & $\mathrm{STOP} \geq 48$ & STOP $\geq 96$ & $\mathrm{STOP} \geq 48$ \\
\hline & $\mathrm{CrCl} \leq 15-29 \mathrm{ml} / \mathrm{min}$ & $\mathrm{STOP} \geq 48$ & $\mathrm{STOP} \geq 48$ & Not indicated & $\mathrm{STOP} \geq 48$ \\
\hline & $\mathrm{CrCl} \leq 15 \mathrm{ml} / \mathrm{min}$ & \multicolumn{4}{|c|}{$\begin{array}{l}\text { Consider measuring drug activity to determine absence of drug } \\
\text { effect }\end{array}$} \\
\hline & RESTART & \multicolumn{4}{|c|}{$\geq 48-72$ after intervention } \\
\hline
\end{tabular}

Minor-bleeding-risk interventions: dental, cataract, glaucoma, endoscopy without biopsy or resection, superficial surgery; low-bleeding-risk interventions: endoscopy with biopsy, prostate biopsy, bladder biopsy, pacemaker or implantable cardioverter-defibrillator implantation, noncoronary angiography, electrophysiological study/catheter ablation; high-bleedingrisk intervention: major surgery, spinal puncture or placement of spinal/epidural catheter, other situations in which complete hemostasis is required

$\mathrm{CrCl}$ Cockcroft-Gault creatinine clearance; and $\mathrm{NA}$ not applicable

*Skip 1 dose of dabigatran or apixaban; no dose of edoxaban or rivaroxaban is skipped

${ }^{\dagger}$ Has not been studied

higher bleeding risk, renal failure or lack of familiarity with dosing guideline [75].

Underdosing of NOACs has been observed in several countries [74, 76-80]. Dosing of rivaroxaban (adjusted according to kidney function) may be simpler than that of other NOACs, which is slightly more limited by various factors (creatinine, weight, age, treatment with P-glycoprotein inhibitors). The main factors associated with underdosing are advanced age, kidney failure, co-morbidities and having a high risk of bleeding and thromboembolic events. Doctors must not choose lower dose of NOACs just out of a fear of bleeding (thus ignoring the risk of stroke) [74]. Under-dosing of NOACs in patients with AF may be associated with reduced effectiveness for stroke prevention, with similar or even increased bleeding than with the standard dose [81]. Anticoagulation monitoring enables personalized and 


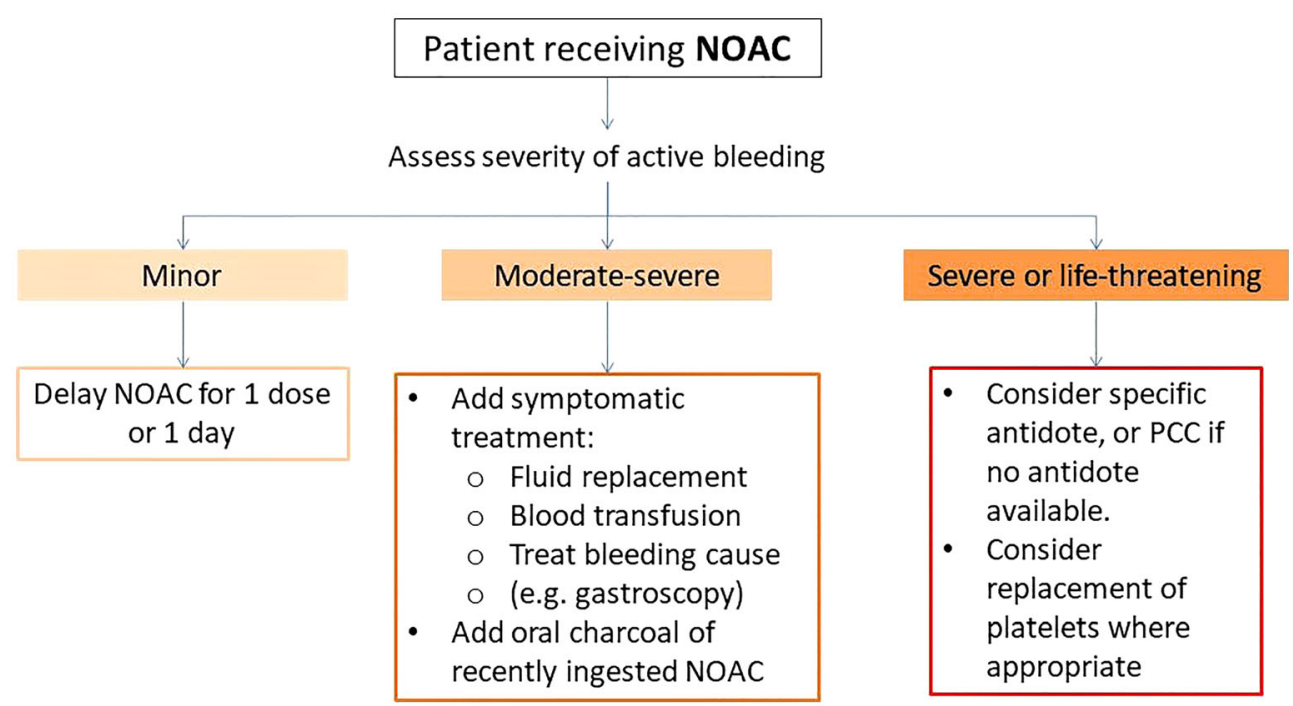

Fig. 7 Management of active bleeding in patients receiving NOAC anticoagulation [42]. FFP fresh frozen plasma, INR international normalized ratio, i.v. intravenous, $N O A C$ non-vitamin $\mathrm{K}$ antagonist oral anticoagulant,

Table 13 Characteristics and dosing of reversal agents [72]

\begin{tabular}{|c|c|c|c|}
\hline Parameter & Andexanet alfa & Idarucizumab & Ciraparantag \\
\hline FDA status & Approved & Approved & $\begin{array}{l}\text { Under FDA } \\
\text { review }\end{array}$ \\
\hline Dose & $\begin{array}{l}\text { Low dose: } 400 \mathrm{mg} \text { IV bolus at a target rate of } 30 \mathrm{mg} / \\
\text { min, then a } 4 \mathrm{mg} / \mathrm{min} \text { continuous infusion for } \\
120 \mathrm{~min}(480 \mathrm{mg}) \\
\text { High dose: } 800 \mathrm{mg} \mathrm{IV} \text { bolus at a target rate of } 30 \mathrm{mg} / \\
\text { min, then an } 8 \mathrm{mg} / \mathrm{min} \text { continuous infusion for } \\
120 \mathrm{~min}(960 \mathrm{mg})\end{array}$ & $\begin{array}{l}5 \mathrm{~g} \text { IV given as two } 50-\mathrm{ml} \text { bolus } \\
\text { infusions with } 2.5 \mathrm{~g} \text { each within } \\
15 \text { min apart }\end{array}$ & $\begin{array}{l}\text { 100-300 mg IV } \\
\text { one time } \\
\text { bolus }\end{array}$ \\
\hline Structure & Modified factor Xa decoy protein & Monoclonal antibody fragment & $\begin{array}{l}\text { Synthetic water- } \\
\text { soluble } \\
\text { molecule }\end{array}$ \\
\hline Mechanism & Binds to the active site of factor $\mathrm{Xa}$ inhibitors & $\begin{array}{l}\text { Binds free and thrombin-bound } \\
\text { dabigatran }\end{array}$ & $\begin{array}{l}\text { Direct binding } \\
\text { to } \\
\text { anticoagulants }\end{array}$ \\
\hline $\begin{array}{l}\text { Onset of } \\
\text { action }\end{array}$ & $2-5 \mathrm{~min}$ & $10-30 \mathrm{~min}$ & $10 \mathrm{~min}$ \\
\hline Half-life & $1 \mathrm{~h}$ & $45 \mathrm{~min}$ & $45 \mathrm{~min}$ \\
\hline
\end{tabular}

*Based on currently available data 


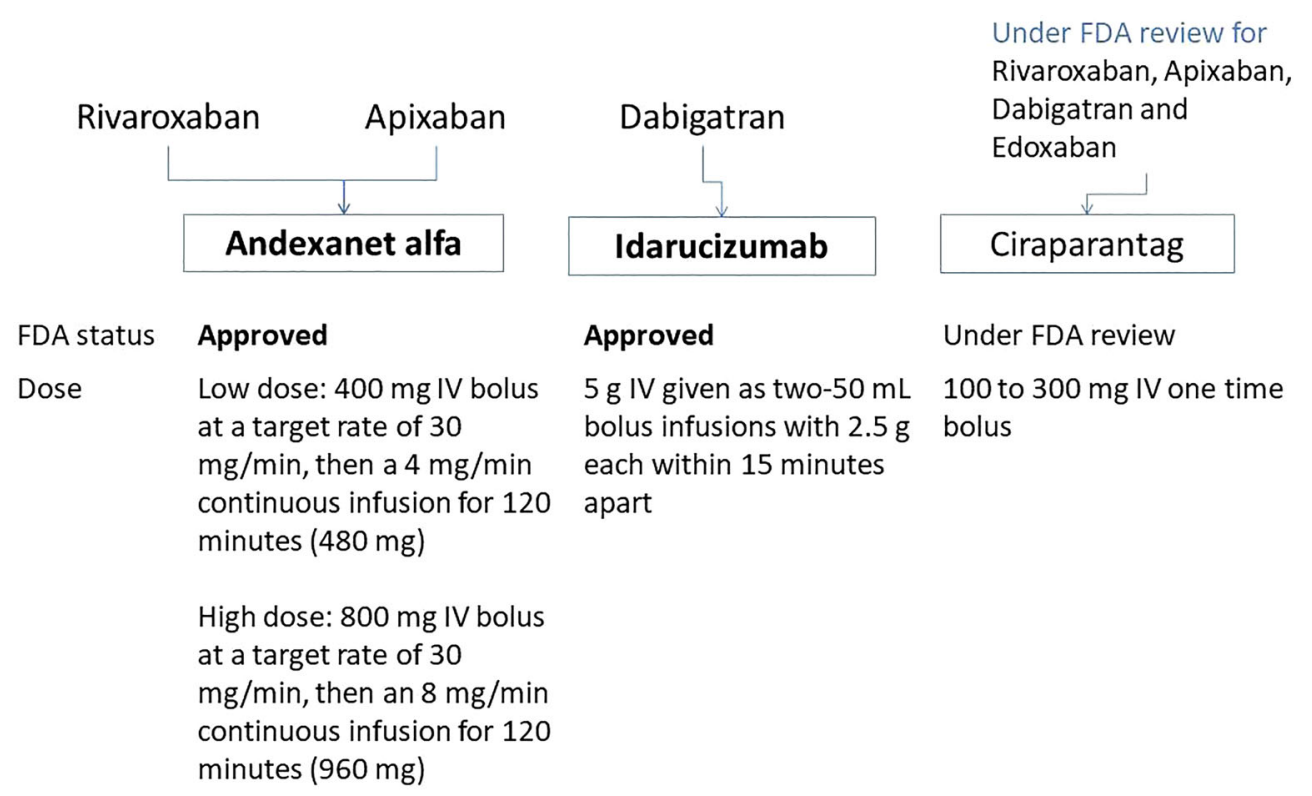

Fig. 8 Dosing regimen of NOAC reversal agents [72]

appropriate off-label under-dosing in NVAF patients on rivaroxaban or apixaban through the measurement of peak plasma concentration (PC) during NOAC use [82].

\section{NOAC IN OTHER CARDIAC CONDITIONS}

The NOACs are contraindicated in atrial fibrillation patients with rheumatic mitral stenosis or mechanical heart valves [83]. Catheter ablation for AF is an unknown and neglected aspect that needs to be highlighted. A prospective study including NOAC-treated patients requiring $\mathrm{AF}$ ablation showed that uninterrupted NOAC therapy led to highly variable and unpredictable initial level of anticoagulation before catheter ablation. Cardiologists, electrophysiologists, and intensivists must be aware of the evidence gaps regarding intraprocedural anticoagulation in uninterrupted NOAC-treated patients. Vigilance should be reinforced regarding bleeding and thrombosis risk while waiting for more laboratory and clinical data for intraprocedural anticoagulation [84].

\section{DRUG-DRUG INTERACTIONS}

Drug-drug interactions of NOACs are respective recommendations are mentioned in Table 14 .

\section{MEASURING NOAC}

Measuring NOAC levels with dedicated tests before surgical or invasive procedures is of paramount importance for patient safety. The tests help to rule in or out clinically relevant concentrations of residual drugs. Although NOAC do not need routine dose adjustment based on laboratory testing, the measurement of their anticoagulant effect may be useful in special situations such as (a) at the time of adverse events (hemorrhage or thrombosis), (b) before antidotes administration, (c) to make decision on thrombolytic therapy in ischemic stroke patients. Whenever drug-to-drug interaction is suspected, (d) in patients with extreme body weight [86].

\section{Best Tests to Monitor NOAC Levels?}

Routine anticoagulation with assays such as prothrombin time (PT), activated partial 
Table 14 Summary of recommendations for drug-drug interactions with NOACs and selected medications [85]

\begin{tabular}{lllll}
\hline Interacting agent & Rivaroxaban & Apixaban & Edoxaban & Dabigatran \\
\hline & P-gp and strong & CYP3A4 and & Anticoagulants, antiplatelets, & P-gp inducers \\
& CYP3A & P-gp & thrombolytics, and selective & \\
inhibitors and & inhibitors & serotonin reuptake inhibitors & \\
inducers & and & (SSRIs)/serotonin & \\
& inducers & norepinephrine reuptake & \\
& & inhibitors (SNRIs) &
\end{tabular}

Antiarrhythmic agents

Dronedarone

Avoid

combination if

$\mathrm{CrCl}<80 \mathrm{ml} /$

$\min$

Combination

is

considered

acceptable

Amiodarone

$\begin{array}{ll}\text { Avoid use if } & \text { Combination } \\ \mathrm{CrCl}<80 \mathrm{ml} / & \text { is } \\ \min & \begin{array}{l}\text { considered } \\ \text { safe }\end{array}\end{array}$

Calcium-channel blockers

Verapamil
Avoid use if
$\mathrm{CrCl}<80 \mathrm{ml} /$
$\min$
is
considered
safe

Combination is considered safe

Reduce dose of edoxaban by $50 \%$
Administer $2 \mathrm{~h}$ before dronedarone
Reduce dose to $75 \mathrm{mg}$ twice daily for $\mathrm{CrCl}$ $30-50 \mathrm{ml} / \mathrm{min}$
Avoid use if
$\mathrm{CrCl}<30 \mathrm{ml} / \mathrm{min}$

Combination considered safe if $\mathrm{CrCl}>50 \mathrm{ml} / \mathrm{min}$

Avoid combination if $\mathrm{CrCl}<50 \mathrm{ml} / \mathrm{min}$ for VTE

and $<30 \mathrm{ml} / \mathrm{min}$ for NVAF

Diltiazem

$\begin{array}{ll}\text { Avoid use if } & \text { Combination } \\ \mathrm{CrCl}<80 \mathrm{ml} / & \text { is } \\ \min & \begin{array}{l}\text { considered } \\ \text { safe }\end{array}\end{array}$

Enzyme inducers

safe
Avoid use if $\mathrm{CrCl}<30 \mathrm{ml} / \mathrm{min}$ for NVAF and $<50 \mathrm{ml} / \mathrm{min}$ for VTE

Combination is considered safe

for VTE

Combination is considered safe

\section{Combination is} considered safe 
Table 14 continued

\begin{tabular}{|c|c|c|c|c|}
\hline Interacting agent & Rivaroxaban & Apixaban & Edoxaban & Dabigatran \\
\hline $\begin{array}{l}\text { Phenytoin, } \\
\text { carbamazepine, } \\
\text { primidone, rifampin, } \\
\text { phenobarbital, St. } \\
\text { John's wort }\end{array}$ & $\begin{array}{l}\text { Avoid } \\
\text { combination; } \\
\text { consider } \\
\text { warfarin }\end{array}$ & & & \\
\hline
\end{tabular}

$\mathrm{CrCl}$ creatinine clearance, $N V A F$ nonvalvular atrial fibrillation, $V T E$ venous thromboembolism

thromboplastin time (aPTT), or thrombin time (TT) may provide limited information of drug concentration in cases of acute bleeding, emergent surgical intervention, need for intravenous thrombolysis, acute intracerebral bleeding, and suspected anticoagulant overdose. Point-of-care testing (POCTs) can offer quick information on NOAC concentration in such instances, allowing for emergency reversal. To detect the plasma concentrations of factor $\mathrm{Xa}$ inhibitors, antifactor Xa chromogenic assays are available, and utilizing these assays, the absence of factor $\mathrm{Xa}$ activity can reliably rule out the presence of clinically significant drug levels [72].

\section{Routine NOAC Monitoring?}

Although NOAC drug levels can be accurately measured, information on the optimal level in specific patient groups (e.g., the elderly, the renally impaired, and those at high risk of bleeding), the appropriate dose adjustment to achieve expected levels, and whether routine laboratory monitoring and dose adjustment will improve clinical outcomes are all lacking. Unmonitored NOAC medication is at least as effective and safe as monitored warfarin therapy, with lower risks of cerebral hemorrhage and mortality, according to evidence from patients with atrial fibrillation who were randomized to NOACs or warfarin. There has to be more research done to see if routine laboratory monitoring is beneficial to patients. Clinicians should continue to administer NOACs in fixed doses without routine monitoring until more data becomes available [87].

\section{Strengths and Limitations}

Clinicians and policymakers must see this document to help reduce the gap between clinical practice and scientific evidence. It offers expert recommendations and newer treatment options for clinicians who are uncertain about prescribing the right NOAC in a specific situation. The principal benefit of this document is to improve the quality of clinical decisions. Although we assembled a panel of clinicians from academic and community settings, as well as urban and rural settings, it does not stand the same for the diverse healthcare practice in India that ranges from poor to very good medical service. Secondly, these recommendations do not include a cost-benefit analysis. Thirdly, the expert group was not multi-disciplinary, and finally, the development of this practical guideline was not as rigorous as compared to a clinical practice guideline (the clinical evidence was not graded).

\section{ACKNOWLEDGEMENTS}

Authorship. All named authors meet the International Committee of Medical Journal Editors (ICMJE) criteria for authorship for this article, take responsibility for the integrity of 
the work as a whole, and have given their approval for this version to be published.

Authors Contributions. The authors acknowledge all the doctors who participated in the Advisory Board meetings which was instrumental in developing the recommendations and final manuscript.

Medical Writing, Editorial and Other Assistance. The authors acknowledge IntelliMed Healthcare Solutions Pvt. Ltd., Maharashtra, India for medical writing support. The authors acknowledge Dr. Vidhya N from Dr. Reddy's Laboratories for medical writing and publication support.

Disclosures. Balbir Singh, Paresh Pai, Harish Kumar, Sheeba George, Sandeep Mahapatra, Vineet Garg, G N Gupta, Kiran Makineni, Gaurav Ganeshwala, Pravin Narkhede are on the advisory board of Dr. Reddy's Laboratories (DRL). Syed MH Naqvi and Kumar Gaurav are employees of DRL. Mohammed YK Hukkeri is an Ex-Employee of DRL.

Compliance with Ethics Guidelines. This article is based on previously conducted studies and does not contain any new studies with human participants or animals performed by any of the authors.

Funding. The journal's Rapid Service Fee was funded by Dr. Reddy's Laboratories, India.

Data Availability. Data sharing is not applicable to this article as no datasets were generated or analyzed during the current study.

Open Access. This article is licensed under a Creative Commons Attribution-NonCommercial 4.0 International License, which permits any non-commercial use, sharing, adaptation, distribution and reproduction in any medium or format, as long as you give appropriate credit to the original author(s) and the source, provide a link to the Creative Commons licence, and indicate if changes were made. The images or other third party material in this article are included in the article's Creative Commons licence, unless indicated otherwise in a credit line to the material. If material is not included in the article's Creative Commons licence and your intended use is not permitted by statutory regulation or exceeds the permitted use, you will need to obtain permission directly from the copyright holder. To view a copy of this licence, visit http://creativecommons.org/licenses/by$\mathrm{nc} / 4.0 /$.

\section{REFERENCES}

1. DVT/PE | boehringer-ingelheim.in [Internet]. https://www.boehringer-ingelheim.in/ cardiovascular/dvtpe. Accessed 10 Dec 2021.

2. Lee AD, Stephen E, Agarwal S, Premkumar P. Venous thrombo-embolism in India. Eur J Vasc Endovasc Surg. 2009;37(4):482-5.

3. Kapoor VK. Venous thromboembolism in India. Natl Med J India. 2010;23(4):193-5.

4. Eikelboom JW, Weitz JI. New anticoagulants. Circulation. 2010;121(13):1523-32.

5. Boehringer Ingelheim. PRADAXA ${ }^{\circledR}$ (dabigatran etexilate). U.S. Food and Drug Administration website. https://www.accessdata.fda.gov/ drugsatfda_docs/label/2021/022512s041lbl.pdf. Revised [6/2021]. Accessed 12 Dec 2021.

6. Kakkar N, Kaur R. Knowledge base of clinicians regarding oral anticoagulant therapy in a teaching institution-a questionnaire survey. J Assoc Physicians India. 2004;52:868-72.

7. van Es N, Coppens M, Schulman S, Middeldorp S, Büller HR. Direct oral anticoagulants compared with vitamin $\mathrm{K}$ antagonists for acute venous thromboembolism: evidence from phase 3 trials. Blood. 2014;124(12):1968-75.

8. Janssen Pharmaceutical Companies. XARELTO ${ }^{\circledR}$ (rivaroxaban). U.S. Food and Drug Administration website. https://www.accessdata.fda.gov/ drugsatfda_docs/label/2021/202439_S035_

022406S037lbl.pdf. Revised [08/2021]. Accessed 12 Dec 2021.

9. Bristol Myers Squibb. ELIQUIS ${ }^{\circledR}$ (apixaban). U.S. Food and Drug Administration website. https:// www.accessdata.fda.gov/drugsatfda_docs/label/ 2021/202155s034lbl.pdf. Revised [04/2021]. Accessed 14 Dec 2021. 
10. Ortel TL, Neumann I, Ageno W, Beyth R, Clark NP, Cuker A, et al. American Society of Hematology 2020 guidelines for management of venous thromboembolism: treatment of deep vein thrombosis and pulmonary embolism. Blood Adv. 2020;4(19):4693-738.

11. Zhou Y, Ma J, Zhu W. Efficacy and safety of direct oral anticoagulants versus warfarin in patients with atrial fibrillation across BMI categories: a systematic review and meta-analysis. Am J Cardiovasc Drugs. 2020;20(1):51-60.

12. Ruff CT, Giugliano RP, Braunwald E, Hoffman EB, Deenadayalu N, Ezekowitz MD, et al. Comparison of the efficacy and safety of new oral anticoagulants with warfarin in patients with atrial fibrillation: a meta-analysis of randomised trials. Lancet. 2014;383(9921):955-62.

13. The Indian consensus guidance on stroke prevention in atrial fibrillation: an emphasis on practical use of nonvitamin $\mathrm{K}$ oral anticoagulants [Internet]. https://www.ncbi.nlm.nih.gov/pmc/articles/ PMC4688441/. Accessed 10 Dec 2021.

14. Mekaj YH, Mekaj AY, Duci SB, Miftari EI. New oral anticoagulants: their advantages and disadvantages compared with vitamin $\mathrm{K}$ antagonists in the prevention and treatment of patients with thromboembolic events. Ther Clin Risk Manag. 2015;11: 967-77.

15. Tritschler T, Méan M, Limacher A, Rodondi N, Aujesky D. Predicting recurrence after unprovoked venous thromboembolism: prospective validation of the updated Vienna Prediction Model. Blood. 2015;126(16):1949-51.

16. Eichinger S, Heinze G, Kyrle PA. d-Dimer levels over time and the risk of recurrent venous thromboembolism: an update of the Vienna Prediction Model. J Am Heart Assoc. 2014;3(1):e000467.

17. Stevens H, Tran H, Gibbs H. Venous thromboembolism: current management. https://www.nps.org. au/australian-prescriber/articles/venous-

thromboembolism-current-management. Accessed 10 Dec 2021.

18. Alhousani M, Malik SU, Abu-Hashyeh A, Poznanski NJ, Al-Hasan S, Roth DF, et al. Using oral anticoagulants among chronic kidney disease patients to prevent recurrent venous thromboembolism: a systematic review and meta-analysis. Thromb Res. 2021;198:103-14.

19. Mainbourg S, Cucherat M, Provencher S, Bertoletti L, Nony P, Gueyffier F, et al. Twice- or once-daily dosing of direct oral anticoagulants, a systematic review and meta-analysis. Thromb Res. 2021;1(197):24-32.
20. Kubitza D, Berkowitz SD, Misselwitz F. Evidencebased development and rationale for once-daily rivaroxaban dosing regimens across multiple indications. Clin Appl Thromb. 2016;22(5):412-22.

21. Camm AJ, Bounameaux H. Edoxaban. Drugs. 2011;71(12):1503-26.

22. Investigators Hokusai-VTE, Büller HR, Décousus $H$, Grosso MA, Mercuri M, Middeldorp S, Prins MH, Raskob GE, Schellong SM, Schwocho L, Segers A, Shi M, Verhamme P, Wells P. Edoxaban versus warfarin for the treatment of symptomatic venous thromboembolism. N Engl J Med. 2013;369(15): 1406-15. https://doi.org/10.1056/NEJMoa1306638.

23. Agnelli G, Buller HR, Cohen A, Curto M, Gallus AS, Johnson M, et al. Apixaban for extended treatment of venous thromboembolism. $\mathrm{N}$ Engl J Med. 2013;368(8):699-708.

24. Agnelli G, Buller HR, Cohen A, Curto M, Gallus AS, Johnson M, et al. Oral apixaban for the treatment of acute venous thromboembolism. N Engl J Med. 2013;369(9):799-808.

25. Patel R. Effective management of venous thromboembolism in the community: non-vitamin $\mathrm{K}$ antagonist oral anticoagulants. Int J Gen Med. 2016;4(9):107-15.

26. Grandone E, Aucella F, Barcellona D, Brunori G, Forneris G, Gresele P, et al. Position paper on the safety/efficacy profile of direct oral anticoagulants in patients with chronic kidney disease: consensus document of Società Italiana di Nefrologia (SIN), Federazione Centri per la diagnosi della trombosi e la Sorveglianza delle terapie Antitrombotiche (FCSA) and Società Italiana per lo Studio dell'Emostasi e della Trombosi (SISET). J Nephrol. 2021;34(1):31-8.

27. Giustozzi M, Franco L, Vedovati MC, Becattini C, Agnelli G. Safety of direct oral anticoagulants versus traditional anticoagulants in venous thromboembolism. J Thromb Thrombolysis. 2019;48(3): 439-53.

28. Sardar P, Chatterjee S, Chaudhari S, Lip GYH. New oral anticoagulants in elderly adults: evidence from a meta-analysis of randomized trials. J Am Geriatr Soc. 2014;62(5):857-64.

29. Gross PL, Chan NC. Thromboembolism in older adults. Front Med. 2021;7:470016.

30. Agnelli G, Becattini C, Meyer G, Muñoz A, Huisman MV, Connors JM, et al. Apixaban for the treatment of venous thromboembolism associated with cancer. N Engl J Med. 2020;382(17):1599-607. 
31. Roberti R, Iannone LF, Palleria C, Curcio A, Rossi M, Sciacqua A, et al. Direct oral anticoagulants: from randomized clinical trials to real-world clinical practice. Front Pharmacol. 2021;12:1105.

32. Young AM, Marshall A, Thirlwall J, Chapman O, Lokare A, Hill C, et al. Comparison of an oral factor $\mathrm{Xa}$ inhibitor with low molecular weight heparin in patients with cancer with venous thromboembolism: results of a randomized trial (SELECT-D). J Clin Oncol. 2018;36(20):2017-23.

33. Raskob GE, van Es N, Verhamme P, Carrier M, Di Nisio M, Garcia D, et al. Edoxaban for the treatment of cancer-associated venous thromboembolism. N Engl J Med. 2018;378(7):615-24.

34. Wang Y, Lv H, Li D, Chen C, Gu G, Sun Y, et al. Efficacy and safety of direct oral anticoagulants for secondary prevention of cancer-associated thrombosis: a systematic review and meta-analysis of randomized controlled trials and prospective cohort studies. Front Pharmacol. 2019;10:773.

35. Stevens SM, Woller SC, Kreuziger LB, Bounameaux H, Doerschug K, Geersing G-J, et al. Antithrombotic therapy for VTE disease: second update of the CHEST guideline and expert panel report. Chest. 2021;160(6):e545-608.

36. Palareti G, Antonucci E, Migliaccio L, Erba N, Marongiu F, Pengo V, et al. Vitamin $\mathrm{K}$ antagonist therapy: changes in the treated populations and in management results in Italian anticoagulation clinics compared with those recorded 20 years ago. Intern Emerg Med. 2017;12(8):1109-19.

37. Palareti G, Leali N, Coccheri S, Poggi M, Manotti C, D'Angelo A, et al. Bleeding complications of oral anticoagulant treatment: an inception-cohort, prospective collaborative study (ISCOAT). Lancet. 1996;348(9025):423-8.

38. HAS-BLED tool - what is the real risk of bleeding in anticoagulation? [Internet]. Am Coll Cardiol. https://www.acc.org/latest-in-cardiology/articles/ 2014/07/18/15/13/http\%3a\%2f\%2fwww.acc.org\% 2flatest-in-cardiology $\% 2$ farticles $\% 2 f 2014 \% 2 f 07 \%$ 2f18\%2f15\%2f13\%2fhas-bled-tool-what-is-the-realrisk-of-bleeding-in-anticoagulation. Accessed 8 Dec 2021.

39. Lane DA, Lip GYH. Use of the CHA2DS2-VASc and HAS-BLED scores to aid decision making for thromboprophylaxis in nonvalvular atrial fibrillation. Circulation. 2012;126(7):860-5.

40. Chao T-F, Lip GYH, Liu C-J, Tuan T-C, Chen S-J, Wang K-L, et al. Validation of a modified CHA2DS2-VASc score for stroke risk stratification in Asian patients with atrial fibrillation. Stroke. 2016;47(10):2462-9.
41. Shields AM, Lip GYH. Choosing the right drug to fit the patient when selecting oral anticoagulation for stroke prevention in atrial fibrillation. J Intern Med. 2015;278(1):1-18.

42. Hindricks G, Potpara T, Dagres N, Arbelo E, Bax JJ, Blomström-Lundqvist C, et al. 2020 ESC guidelines for the diagnosis and management of atrial fibrillation developed in collaboration with the European Association for Cardio-Thoracic Surgery (EACTS): the Task Force for the diagnosis and management of atrial fibrillation of the European Society of Cardiology (ESC) developed with the special contribution of the European Heart Rhythm Association (EHRA) of the ESC. Eur Heart J. 2021;42(5):373-498.

43. Wang K-L, Chiu C-C, Su-Yin Tan D, Lin C-Y, Lai E-Y, Goto S, et al. Once- or twice-daily non-vitamin $\mathrm{K}$ antagonist oral anticoagulants in Asian patients with atrial fibrillation: a meta-analysis of randomized controlled trials. J Formos Med Assoc. 2017;116(8):591-8.

44. Clemens A, Noack H, Brueckmann M, Lip GYH. Twice- or once-daily dosing of novel oral anticoagulants for stroke prevention: a fixed-effects metaanalysis with predefined heterogeneity quality criteria. PLoS One. 2014;9(6):e99276.

45. Emren SV, Zoghi M, Berilgen R, Özdemir İH, Çelik $\mathrm{O}$, Çetin N, et al. Safety of once- or twice-daily dosing of non-vitamin $\mathrm{K}$ antagonist oral anticoagulants (NOACs) in patients with nonvalvular atrial fibrillation: a NOAC-TR study. Bosn J Basic Med Sci. 2018;18(2):185-90.

46. Amara W, Antoniou S. Benefits of once-daily dosing with non-vitamin $\mathrm{K}$ antagonist oral anticoagulants in patients with atrial fibrillation. Eur Heart J Suppl. 2016;18(Suppl D):D1-6.

47. Antoniou S, Amara W. Once-daily rivaroxaban for long-term stroke prevention in patients with atrial fibrillation. Eur Heart J Suppl. 2016;18(Suppl D):D715.

48. Ageno W, Beyer-Westendorf J, Rubboli A. Onceversus twice-daily direct oral anticoagulants in nonvalvular atrial fibrillation. Expert Opin Pharmacother. 2017;18(13):1325-32.

49. Lee S-R, Choi E-K, Han K-D, Jung J-H, Oh S, Lip GYH. Comparison of once-daily administration of edoxaban and rivaroxaban in Asian patients with atrial fibrillation. Sci Rep. 2019;9(1):6690.

50. Shlofmitz E, Shlofmitz R, Lee MS. The role of novel oral anticoagulants and antiplatelet therapy after percutaneous coronary intervention: individualizing therapy to optimize outcomes. Korean Circ J. 2019;49(8):645-56. 
51. Hansen ML, Sørensen R, Clausen MT, Fog-Petersen ML, Raunsø J, Gadsbøll N, et al. Risk of bleeding with single, dual, or triple therapy with warfarin, aspirin, and clopidogrel in patients with atrial fibrillation. Arch Intern Med. 2010;170(16):1433-41.

52. van Rein N, Heide-Jørgensen U, Lijfering WM, Dekkers OM, Sørensen HT, Cannegieter SC. Major bleeding rates in atrial fibrillation patients on single, dual, or triple antithrombotic therapy. Circulation. 2019;139(6):775-86.

53. Kumbhani DJ, Cannon CP, Beavers CJ, Bhatt DL, Cuker A, Gluckman TJ, et al. 2020 ACC expert consensus decision pathway for anticoagulant and antiplatelet therapy in patients with atrial fibrillation or venous thromboembolism undergoing percutaneous coronary intervention or with atherosclerotic cardiovascular disease. J Am Coll Cardiol. 2021;77(5):629-58.

54. Gibson CM, Mehran R, Bode C, Halperin J, Verheugt FW, Wildgoose $\mathrm{P}$, et al. Prevention of bleeding in patients with atrial fibrillation undergoing PCI. N Engl J Med. 2016;375(25):2423-34.

55. Oldgren J, Steg PG, Hohnloser SH, Lip GYH, Kimura T, Nordaby M, et al. Dabigatran dual therapy with ticagrelor or clopidogrel after percutaneous coronary intervention in atrial fibrillation patients with or without acute coronary syndrome: a subgroup analysis from the RE-DUAL PCI trial. Eur Heart J. 2019;40(19):1553-62.

56. Heine GH, Brandenburg V, Schirmer SH. Oral anticoagulation in chronic kidney disease and atrial fibrillation. Dtsch Arztebl Int. 2018;115(17): 287-94.

57. Chiang C-E, Okumura K, Zhang S, Chao T-F, Siu C-W, Wei Lim T, et al. 2017 consensus of the Asia Pacific Heart Rhythm Society on stroke prevention in atrial fibrillation. J Arrhythmia. 2017;33(4): 345-67.

58. Nielsen PB, Lane DA, Rasmussen LH, Lip GYH, Larsen TB. Renal function and non-vitamin $\mathrm{K}$ oral anticoagulants in comparison with warfarin on safety and efficacy outcomes in atrial fibrillation patients: a systemic review and meta-regression analysis. Clin Res Cardiol. 2015;104(5):418-29.

59. Calsolaro V, Okoye C, Antognoli R, Dell'Agnello U, Calabrese AM, Monzani F. Long-term effectiveness and safety of anticoagulation therapy in oldest old, frail people with atrial fibrillation. Eur J Intern Med. 2021;86:91-7.

60. Rutherford OW, Jonasson C, Ghanima W, Söderdahl F, Halvorsen S. Effectiveness and safety of oral anticoagulants in elderly patients with atrial fibrillation. Heart. 2021. https://doi.org/10.1136/ heartjnl-2020-318753.

61. Chen A, Stecker E, Warden BA. Direct oral anticoagulant use: a practical guide to common clinical challenges. J Am Heart Assoc. 2020;9(13):e017559.

62. Brar T, Chua D. Direct-acting oral anticoagulant choice for stroke prevention in obese patients with atrial fibrillation. Can J Cardiol. 2021;37(9): 1489-92.

63. Barakat AF, Jain S, Masri A, Alkukhun L, Senussi M, Sezer A, et al. Outcomes of direct oral anticoagulants in atrial fibrillation patients across different body mass index categories. JACC Clin Electrophysiol. 2021;7(5):649-58.

64. Thangjui S, Kewcharoen J, Yodsuwan R, Trongtorsak A, Thyagaturu H, Shrestha B, Winans ARM, Bischof E. Efficacy and safety of direct oral anticoagulant in morbidly obese patients with atrial fibrillation: systematic review and meta-analysis. Eur Heart J Cardiovasc Pharmacother. 2021. https://doi. org/10.1093/ehjcvp/pvab026.

65. Lachant DJ, Bach C, Fe A, White RJ, Lachant NA. Direct oral anticoagulant therapy in patients with morbid obesity after intermediate- or high-risk pulmonary emboli. ERJ Open Res [Internet]. 2021;7(1). https://openres.ersjournals.com/ content/7/1/00554-2020. Accessed 2 Dec 2021.

66. Martin KA, Beyer-Westendorf J, Davidson BL, Huisman MV, Sandset PM, Moll S. Use of direct oral anticoagulants in patients with obesity for treatment and prevention of venous thromboembolism: updated communication from the ISTH SSC Subcommittee on Control of Anticoagulation. J Thromb Haemost. 2021;19(8):1874-82.

67. Elshafei MN, Mohamed MFH, El-Bardissy A, Ahmed $\mathrm{MB}$, Abdallah I, Elewa $\mathrm{H}$, et al. Comparative effectiveness and safety of direct oral anticoagulants compared to warfarin in morbidly obese patients with acute venous thromboembolism: systematic review and a meta-analysis. J Thromb Thrombolysis. 2021;51(2):388-96.

68. Savelieva I, Camm AJ. Practical considerations for using novel oral anticoagulants in patients with atrial fibrillation. Clin Cardiol. 2014;37(1):32-47.

69. Schulman S, Crowther MA. How I treat with anticoagulants in 2012: new and old anticoagulants, and when and how to switch. Blood. 2012;119(13): 3016-23.

70. Barnes GD, Mouland E. Peri-procedural management of oral anticoagulants in the DOAC era. Prog Cardiovasc Dis. 2018;60(6):600-6. 
71. Douketis JD, Spyropoulos AC, Duncan J, Carrier M, Le Gal G, Tafur AJ, et al. Perioperative management of patients with atrial fibrillation receiving a direct oral anticoagulant. JAMA Intern Med. 2019;179(11):1469-78.

72. Mujer MTP, Rai MP, Atti V, Dimaandal IL, Chan AS, Shrotriya S, et al. An update on the reversal of nonvitamin $\mathrm{K}$ antagonist oral anticoagulants. Adv Hematol. 2020;2020:e7636104.

73. Dalal JJ, Dhall A, Bhave A. Current perspective on use of NOAC in clinical practice in India. J Assoc Physicians India. 2016;64(4):56-65.

74. Fernández CS, Gullón A, Formiga F. The problem of underdosing with direct-acting oral anticoagulants in elderly patients with nonvalvular atrial fibrillation. J Comp Eff Res. 2020;9(7):509-23.

75. Sanghai S, Wong C, Wang Z, Clive P, Tran W, Waring $M$, et al. Rates of potentially inappropriate dosing of direct-acting oral anticoagulants and associations with geriatric conditions among older patients with atrial fibrillation: the SAGE-AF study. J Am Heart Assoc. 2020;9(6):e014108.

76. Ferrat E, Fabre J, Galletout P, Boutin E, Breton JL, Renard V, et al. Inappropriate direct oral anticoagulant prescriptions in patients with non-valvular atrial fibrillation: cross-sectional analysis of the French CACAO cohort study in primary care. Br J Gen Pract. 2021;71(703):e134-9.

77. Masunaga N, Abe M, Ogawa H, Aono Y, Ikeda S, Doi $\mathrm{K}$, et al. Current status, time trends and outcomes of combination therapy with oral anticoagulant and antiplatelet drug in patients with atrial fibrillation the Fushimi AF registry. Circ J. 2018;82(12): 2983-91.

78. Tütüncü S, Olma M, Kunze C, Dietzel J, Schurig J, Fiessler C, et al. Off-label-dosing of non-vitamin K-dependent oral antagonists in AF patients before and after stroke: results of the prospective multicenter Berlin Atrial Fibrillation Registry. J Neurol. 2021. https://doi.org/10.1007/s00415-021-10866-2 (cited 2 Dec 2021).

79. Eschler CM, Antelo A, Funk G-C, Exadaktylos AK, Lindner G. High fluctuation between anticoagulants, frequent off-label dosing, and no difference concerning outcomes: results of a reallife cohort study. Am J Med. 2021;134(3):e165-70.

80. Moudallel S, Cornu P, Dupont A, Steurbaut S. Determinants for under- and overdosing of direct oral anticoagulants and physicians' implementation of clinical pharmacists' recommendations. Br J Clin Pharmacol. 2021. https://doi.org/10.1111/bcp. 15017.

81. Beyer-Westendorf J, Fay M, Amara W. The importance of appropriate dosing of nonvitamin $\mathrm{K}$ antagonist oral anticoagulants for stroke prevention in patients with atrial fibrillation. TH Open. 2021;5(3):e353-62.

82. Suwa M, Morii I, Kino M. Rivaroxaban or apixaban for non-valvular atrial fibrillation - efficacy and safety of off-label under-dosing according to plasma concentration. Circ J. 2019;83(5):991-9.

83. Andrade JG, Meseguer E, Didier R, Dussault C, Weitz JI. Non-vitamin K antagonist oral anticoagulants in atrial fibrillation patients with bioprosthetic valves. Expert Rev Cardiovasc Ther. 2018;23: $1-6$.

84. Martin A-C, Lessire S, Leblanc I, Dincq A-S, Philip I, Gouin-Thibault I, et al. Periprocedural management of anticoagulation for atrial fibrillation catheter ablation in direct oral anticoagulant-treated patients. Clin Cardiol. 2018;41(5):646-51.

85. Wiggins BS, Dixon DL, Neyens RR, Page RL, Gluckman TJ. Select drug-drug interactions with direct oral anticoagulants. J Am Coll Cardiol. 2020;75(11):1341-50.

86. Tripodi A, Marongiu F, Moia M, Palareti G, Pengo V, Poli $\mathrm{D}$, et al. The vexed question of whether or not to measure levels of direct oral anticoagulants before surgery or invasive procedures. Intern Emerg Med. 2018;13(7):1029-36.

87. Eikelboom JW, Quinlan DJ, Hirsh J, Connolly SJ, Weitz JI. Laboratory monitoring of non-vitamin K antagonist oral anticoagulant use in patients with atrial fibrillation: a review. JAMA Cardiol. 2017;2(5):566-74. 